\title{
An Improved Genetic Algorithm with Average-Bound Crossover and Wavelet Mutation Operations
}

\author{
S.H. Ling and F.H.F. Leung \\ Centre for Multimedia Signal Processing, Department of Electronic and Information Engineering, \\ The Hong Kong Polytechnic University, Hung Hom, Kowloon, Hong Kong
}

Abstract: This paper presents a real-coded genetic algorithm (RCGA) with new genetic operations (crossover and mutation). They are called the average-bound crossover (ABX) and wavelet mutation (WM). By introducing the proposed genetic operations, both the solution quality and stability are better than the RCGA with conventional genetic operations. A suite of benchmark test functions are used to evaluate the performance of the proposed algorithm. Application examples on economic load dispatch and tuning an associative-memory neural network are used to show the performance of the proposed RCGA.

Keywords: Crossover, mutation, real-coded genetic algorithm, associative-memory neural network, and economic load dispatch.

\section{INTRODUCTION}

Genetic algorithm (GA) is one evolutionary computation technique [9] that can tackle complex optimization problems [9, 17, 23]. It has been applied in different areas such as fuzzy control [13-14], tuning of neural or neural fuzzy network [15-16], path planning [11], greenhouse climate control [1], economic load dispatch [2, 27], etc. Traditional binary GA [5, 9, 19, 25] has some drawbacks when applying to multidimensional and high-precision numerical problems. The situation can be improved if GA in real numbers is used. Each chromosome is coded as a vector of floating point numbers that has the same length as the solution vector. A large domain can thus be handled. Much research effort has been spent to improve the performance of real-coded GA (RCGA). In general, RCGA involves three operations: selection, crossover and mutation. The selection operation is used to select the chromosomes from the population with respect to some probability distribution based on fitness values. The crossover operation is used to combine the information of the selected chromosomes (parents) and generate the offspring. The mutation 
operation is used to change the offspring genes. Selection schemes such as rank-based selection, elitist strategies, steady-state election and tournament selection were reported [5]. Recently, different crossover operations for RCGA have been proposed to improve the efficiency of the algorithm. The extended intermediate recombination (crossover) (EIX) was proposed by Mühlenbein et. al. [20]. The genes (variables) of the offspring are chosen somewhere between the genes of the parents. It is capable of producing any point within a hypercube slightly larger than that defined by the parents. The unimodal normal distribution crossover (UNDX) was proposed by Ono et. al. [12, 22] for handling multimodal functions and non-separability problems. UNDX mixes the parental information and shows a good searching ability. However, it changes the fundamental concept that the crossover operation should combine the parents to generate offspring, not mixing the parents. The blend crossover (BLX- $\alpha)$ was proposed by Eshelman et. al. [7], which combines the parents to reproduce offspring. It shows a good searching ability for separable functions. However, BLX- $\alpha$ has difficulty in handling non-separability optimisation problems. Also, the above crossover operations are not suitable for optimisation problems with the optimal point located near the domain boundary. For mutation operations, the uniform mutation and nonuniform mutation can be found [19, 21]. The uniform mutation is to change the value of a randomly selected gene to a value between its upper and lower bounds. The non-uniform mutation is capable of fine-tuning the parameters by increasing or decreasing the value of a randomly selected gene with respect to a weighted random number. The weight is usually a monotonic decreasing function of the number of iteration.

In this paper, new genetic operations of crossover and mutation are proposed. The crossover operation is called the average-bound crossover ( $\mathrm{ABX}$ ), which combines the average crossover and bound crossover. The average crossover manipulates the genes of the selected parents, the minimum, and the maximum possible values of the genes. The bound crossover is capable of moving the offspring near the domain boundary. On realizing the ABX operation, the offspring spreads over the domain so that a higher chance of reaching the global optimum can be obtained. The proposed mutation operation is called the wavelet mutation (WM), which applies the wavelet theory $[3-4,18]$ to realize the mutation. Wavelet is a tool to model seismic signals by combining dilations and translations of a simple, oscillatory function (mother wavelet) of a finite duration. The wavelet function has two properties: 1) the function integrates to zero, and 2) it is square integrable, or equivalently has finite energy. Thanks to the properties of the wavelet, the convergence and solution stability are improved. By introducing these genetic operations, the RCGA performs more efficiently and provides a faster convergence than the RCGA with conventional genetic operations in a suite of 18 benchmark test functions [6, 8, 24, 30]. In addition, the RCGA with the proposed operations gives smaller standard deviations of results, i.e. the 
solution quality of the RCGA with the proposed operations is more stable. An experimental study will be made to evaluate the searching ability of the proposed mutation. Also, the sensitivity of the parameter in WM and the sensitivity of the genes' initial range for the proposed RCGA to the searching performance will be discussed. Application examples on economic load dispatch and tuning an associative-memory neural network are also given to show the performance of the proposed RCGA.

This paper is organized as follows. Section II presents the operation of the proposed genetic operations. Experimental studies and analysis are discussed in Section III. 18 benchmark test functions will be used to evaluate the performance of the proposed method. Application examples on economic load dispatch and tuning an associative memory neural network are given in Section IV. A conclusion will be drawn in Section V.

\section{Average-Bound Crossover AND WAVELEt MutATion For RCGA}

The Real-Coded Genetic Algorithm (RCGA) process [5, 19, 25] is shown in Fig. 1. First, a set of population of chromosomes $P$ is created. Each chromosome $\mathbf{p}$ contains some genes (variables). Second, the chromosomes are evaluated by a defined fitness function. The better chromosomes will return higher fitness function values in this process. Third, some of the chromosomes are selected to undergo genetic operations for reproduction by the method of normalized geometric ranking [10]. Normalized geometric ranking is a selection based on a nonstationary penalty function, which is a function of the generation number. As the number of generation increases, the penalty increases that puts more and more selective pressure on the RCGA to find the feasible solution. In general, a higher-rank chromosome will have a higher chance to be selected. Fourth, genetic operations of crossover are performed. The crossover operation is mainly for exchanging information between two parents that are obtained by the selection operation. In the crossover operation, one of the parameters is the probability of crossover $p_{c}$ which gives the expected number $p_{c} \times$ pop_size (where $p o p_{\text {_ }}$ size is the number of chromosomes in the population) of chromosomes that undergo the crossover operation in a generation. We propose a new crossover operation here. First, four chromosomes are generated (instead of two chromosomes in the conventional RCGA) from two selected parents. Second, the best two offspring in terms of the fitness value will be selected to replace their parents. After the crossover operation, the mutation operation follows. It operates with a parameter called the probability of mutation $\left(p_{m}\right)$. The mutation operation is to change the genes of the chromosomes in the population such that the features inherited from their parents can be changed. After going through the mutation operation, 
the new offspring will be evaluated using the fitness function. The new population will be formed when the new offspring replaces the chromosome with the smallest fitness value. After the operations of selection, crossover and mutation, a new population is generated. This new population will repeat the same process. Such an iterative process will be terminated when a defined condition is met. The details about the proposed crossover and mutation operations are given below.

\section{A. Average-bound crossover operation}

The crossover operation is mainly for exchanging information from the two parents, chromosomes $\mathbf{p}_{1}$ and $\mathbf{p}_{2}$, obtained in the selection process. The two parents will eventually produce two offspring. The average-bound crossover (ABX) comprises two operations: average crossover and bound crossover.

\section{1) Average crossover}

$$
\begin{aligned}
\mathbf{o}_{\mathbf{s}_{c}^{1}} & =\frac{\left(\mathbf{p}_{1}+\mathbf{p}_{2}\right)}{2} \\
\mathbf{o}_{\mathbf{s}_{c}^{2}} & =\frac{\left(\mathbf{p}_{\max }+\mathbf{p}_{\min }\right)\left(1-w_{a}\right)+\left(\mathbf{p}_{1}+\mathbf{p}_{2}\right) w_{a}}{2}
\end{aligned}
$$

\section{2) Bound crossover}

$$
\begin{aligned}
& \mathbf{0}_{\mathbf{s}_{c}^{3}}=\mathbf{p}_{\text {max }}\left(1-w_{b}\right)+\max \left(\mathbf{p}_{1}, \mathbf{p}_{2}\right) w_{b} \\
& \mathbf{o}_{\mathbf{s}_{c}^{4}}=\mathbf{p}_{\text {min }}\left(1-w_{b}\right)+\min \left(\mathbf{p}_{1}, \mathbf{p}_{2}\right) w_{b}
\end{aligned}
$$

where

$$
\begin{aligned}
& \mathbf{0}_{\mathbf{s}_{c}^{k}}=\left[\begin{array}{llll}
O_{s_{1}^{k}} & o_{s_{2}^{k}} & \cdots & o_{s_{\text {no }}^{k} \text { vars }}
\end{array}\right], k=1,2,3,4 . \\
& \mathbf{p}_{i}=\left[\begin{array}{llllll}
p_{i_{1}} & p_{i_{2}} & \cdots & p_{i_{j}} & \cdots & p_{i_{\text {no vars }}}
\end{array}\right], i=1,2 ; j=1,2, \ldots, \text { no_vars },
\end{aligned}
$$

$$
\operatorname{para}_{\min }^{j} \leq p_{i_{j}} \leq \operatorname{para}_{\max }^{j},
$$

$\mathbf{p}_{\max }=\left[\begin{array}{llll}\text { para }_{\max }^{1} & \text { para }_{\max }^{2} & \cdots & \text { para }_{\max }^{\text {no_vars }}\end{array}\right]$,

$\mathbf{p}_{\min }=\left[\begin{array}{llll}\text { para }_{\min }^{1} & \text { para }_{\min }^{2} & \cdots & \text { para }_{\min }^{\text {no-vars }}\end{array}\right]$,

no_vars denotes the number of variables to be tuned; $\operatorname{para}_{\min }^{j}$ and $\operatorname{para}_{\max }^{j}$ are the minimum and maximum values of $p_{i_{j}}$ respectively for all $i ; w_{a}, w_{b} \in\left[\begin{array}{ll}0 & 1\end{array}\right]$ denotes the user-defined weight for average crossover and bound crossover respectively, $\max \left(\mathbf{p}_{1}, \mathbf{p}_{2}\right)$ denotes the vector with each element obtained by taking the maximum between the corresponding element of $\mathbf{p}_{1}$ and $\mathbf{p}_{2}$. For 
instance, $\max \left(\left[\begin{array}{lll}1 & -2 & 3\end{array}\right],\left[\begin{array}{lll}2 & 3 & 1\end{array}\right]\right)=\left[\begin{array}{lll}2 & 3 & 3\end{array}\right]$. Similarly, $\min \left(\mathbf{p}_{1}, \mathbf{p}_{2}\right)$ gives a vector by taking the minimum value. For instance, $\min \left(\left[\begin{array}{lll}1 & -2 & 3\end{array}\right],\left[\begin{array}{lll}2 & 3 & 1\end{array}\right]\right)=\left[\begin{array}{lll}1 & -2 & 1\end{array}\right]$. Among $\mathbf{o}_{\mathbf{s}_{c}^{1}}$ to $\mathbf{o}_{s_{c}^{4}}$, the two with the largest fitness values are used as the offspring of the crossover operation. These two offspring are put back into the population to replace their parents.

The rationale behind the $\mathrm{ABX}$ is that if the offspring spreads over the domain, a higher chance of reaching the global optimum can be obtained. As seen from (1) to (4): The average crossover will move the offspring near the centre region of the concerned domain (as $w_{a}$ in (2) approaches 1, $\mathbf{o}_{\mathbf{s}_{c}^{2}}$ approaches $\left(\mathbf{p}_{1}+\mathbf{p}_{2}\right) / 2$, which is the average of the selected parents; and as $w_{a}$ approaches 0, $\mathbf{o}_{s_{c}^{2}}$ approaches $\left(\mathbf{p}_{\max }+\mathbf{p}_{\min }\right) / 2$, which is the average of the domain boundary), while bound crossover will move the offspring near the domain boundary (as $w_{b}$ in (3) and (4) approaches $0, \mathbf{o}_{\mathbf{s}_{c}^{3}}$ and $\mathbf{o}_{\mathbf{s}_{c}^{4}}$ approaches $\mathbf{p}_{\max }$ and $\mathbf{p}_{\min }$ respectively). The result of the crossover depends on the values of the weights $w_{a}$ and $w_{b}$. Their values depend on the optimisation problem and are chosen by trial and error. Fig. 2 shows an example indicating the relationship between the parents and the offspring under different values of the weights. In this figure, the line represents the domain of a gene. The end points of the line represent the minimum and maximum values of the gene. The dot $(\bullet)$ represents the parents and the circle-dot $(\odot)$ represents the offspring. The values in brackets represent the values of the genes under different values of the weights. For example, when $p_{1}=1$ and $p_{2}=4$, referring to (1) and (2), the offspring $\mathbf{o}_{\mathbf{s}_{c}^{1}}$ and $\mathbf{o}_{\mathbf{s}_{c}^{2}}$ should be equal to 2.5 and 3.75 respectively when $w_{a}=0.5$. According to (1) to (4), the offspring is generated. We can see how the offspring spreads over the domain under different values of $w_{a}$ and $w_{b}$. Changing the value of the weight $w_{a}$ will change the characteristics of the average crossover operation. In this paper, the value of $w_{a}$ is arbitrarily set at 0.5 . On the other hand, changing the value of the weight $w_{b}$ will change the characteristics of the bound crossover operation.

\section{B. Wavelet mutation operation}

Before presenting the wavelet mutation operation, we first discuss the basic wavelet theory.

\section{1) Wavelet theory}

Certain seismic signals can be modelled by combining translations and dilations of an oscillatory function with a finite duration called a "wavelet". A continuous-time function $\psi(x)$ is called a "mother wavelet" or "wavelet” if it satisfies the following properties: 


\section{Property 1:}

$\int_{-\infty}^{+\infty} \psi(x) d x=0$

In other words, the total positive momentum of $\psi(x)$ is equal to the total negative momentum of $\psi(x)$.

Property 2:

$\int_{-\infty}^{+\infty}|\psi(x)|^{2} d x<\infty$

where most of the energy in $\psi(x)$ is confined to a finite duration and bounded. The Morlet wavelet (as shown in Fig .3) is an example mother wavelet, which was proposed by Daubechies [4]: $\psi(x)=e^{-x^{2} / 2} \cos (5 x)$

The Morlet wavelet integrates to zero (Property 1). Over 99\% of the total energy of the function is contained in the interval of $-2.5 \leq x \leq 2.5$ (Property 2).

In order to control the magnitude and the position of $\psi(x)$, we define $\psi_{a, b}(x)$ as follows:

$$
\psi_{a, b}(x)=\frac{1}{\sqrt{a}} \psi\left(\frac{x-b}{a}\right)
$$

where $a$ is the dilation parameter and $b$ is the translation parameter. Notice that

$\psi_{1,0}(x)=\psi(x)$

As

$\psi_{a, 0}(x)=\frac{1}{\sqrt{a}} \psi\left(\frac{x}{a}\right)$,

it follows that $\psi_{a, 0}(x)$ is an amplitude-scaled version of $\psi(x)$. Fig. 4 shows different dilations of the Morlet wavelet. The amplitude of $\psi_{a, 0}(x)$ will be scaled down as the dilation parameter $a$ increases. This property is used to do the mutation operation in order to enhance the searching performance.

\section{2) Wavelet mutation}

The mutation operation is to change the genes of the chromosomes inherited from their parents. In general, various methods like uniform mutation or non-uniform mutation $[19,21]$ can be employed to realize the mutation operation. We propose a Wavelet Mutation (WM) operation based on the wavelet theory, which exhibits a fine-tuning ability. The details of the operation are as follows. Every gene of the chromosomes will have a chance to mutate governed by a probability of mutation, $p_{m} \in\left[\begin{array}{ll}0 & 1\end{array}\right]$, which is defined by the user. This probability gives an expected number $\left(p_{m} \times\right.$ pop_size $\times$ no_vars $)$ of genes that undergo the mutation. For each gene, a random number 
between 0 and 1 will be generated such that if it is less than or equal to $p_{m}$, the mutation will take place on that gene which is updated instantly. If $\mathbf{0}_{\mathrm{s}}=\left[\begin{array}{llll}O_{s_{1}}, & O_{s_{2}}, \ldots, o_{s_{\text {no }} \text { vars }}\end{array}\right]$ is the selected chromosome and the element $o_{s_{j}}$ is randomly selected for mutation (the value of $o_{s_{j}}$ is inside

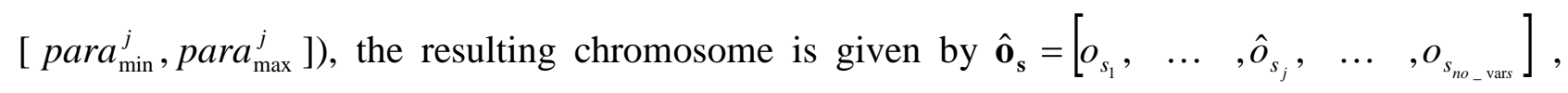
where $j \in 1,2, \ldots$ no_vars, and

$\hat{o}_{s_{j}}=\left\{\begin{array}{l}o_{s_{j}}+\delta \times\left(\text { para }_{\max }^{j}-o_{s_{j}}\right) \text { if } \delta>0 \\ o_{s_{j}}+\delta \times\left(o_{s_{j}}-\text { para }_{\min }^{j}\right) \text { if } \delta \leq 0\end{array}\right.$,

$\delta=\psi_{a, 0}(\varphi)$

$\delta=\frac{1}{\sqrt{a}} \psi\left(\frac{\varphi}{a}\right)$

By using the Morlet wavelet in (11) as the mother wavelet,

$$
\delta=\frac{1}{\sqrt{a}} e^{-\left(\frac{\varphi}{a}\right)^{2} / 2} \cos \left(5\left(\frac{\varphi}{a}\right)\right)
$$

where $\varphi \in[-2.5,2.5]$ is randomly generated. If $\delta$ is positive $(\delta>0)$ approaching 1 , the mutated gene will tend to the maximum value of $o_{s_{j}}$. Conversely, when $\delta$ is negative ( $\left.\delta \leq 0\right)$ approaching -1 , the mutated gene will tend to the minimum value of $o_{s_{j}}$. A larger value of $|\delta|$ gives a larger searching space for $o_{s_{j}}$. When $|\delta|$ is small, it gives a smaller searching space for fine-tuning the gene. Referring to Property 1 of the wavelet, the sum of the positive $\delta$ is equal to the sum of the negative $\delta$ when the number of samples is large and $\varphi$ is randomly generated. That is,

$\frac{1}{N} \sum_{N} \delta=0$ for $N \rightarrow \infty$,

where $N$ is the number of samples.

Hence, the overall positive mutation and the overall negative mutation throughout the evolution are nearly the same. This property gives better solution stability (smaller standard deviation of the solution values upon many trials). As over $99 \%$ of the total energy of the mother wavelet function is contained in the interval $[-2.5,2.5], \varphi$ can be generated from $[-2.5,2.5]$ randomly. The value of the dilation parameter $a$ can be set to vary with the value of $\frac{\tau}{T}$ in order to meet the fine-tuning purpose, where $T$ is the total number of iteration and $\tau$ is the current number of iteration. In order to perform a local search when $\tau$ is large, the value of $a$ should increase as $\frac{\tau}{T}$ increases so as to 
reduce the significance of the mutation. Hence, a monotonic increasing function governing $a$ and $\frac{\tau}{T}$ is proposed as follows.

$a=e^{-\ln (g) \times\left(1-\frac{\tau}{T}\right)^{5}+\ln (g)}$

where $\zeta$ is the shape parameter of the monotonic increasing function, $g$ is the upper limit of the parameter $a$. In this paper, $g$ is set as 10000 . The effects of the various values of the shape parameter $\zeta$ to $a$ with respect to $\frac{\tau}{T}$ are shown in Fig. 5. The value of $a$ is between 1 and 10000 . Referring to (18), the maximum value of $\delta$ is 1 when the random number of $\varphi=0$ and $a=1\left(\frac{\tau}{T}=0\right)$. Then referring to (15), the offspring gene $\hat{o}_{s_{j}}=o_{s_{j}}+1 \times\left(\operatorname{para}_{\max }^{j}-o_{s_{j}}\right)=\operatorname{para}_{\max }^{j}$. It ensures that a large search space for the mutated gene is given. When the value $\frac{\tau}{T}$ is near to 1 , the value of $a$ is so large that the maximum value of $\delta$ will become very small. For example, at $\frac{\tau}{T}=0.9$ and $\zeta=1$, the dilation parameter $a=4000$. If the random value of $\varphi$ is zero, the value of $\delta$ will be equal to 0.0158. With $\hat{o}_{s_{j}}=o_{s_{j}}+0.0158 \times\left(\right.$ para $\left._{\max }^{j}-o_{s_{j}}\right)$, a small searching space for the mutated gene is given for fine-tuning.

\section{Choosing the parameters}

We can regard the RCGA is seeking a balance between the exploration of new regions and the exploitation of the already sampled regions in the search space. This balance, which critically controls the performance of the RCGA, is governed by the right choices of the control parameters: the probability of crossover $\left(p_{c}\right)$, the probability of mutation $\left(p_{m}\right)$, the population size (pop_size), the weights of the proposed crossover $\left(w_{a}, w_{b}\right)$ and the shape parameter $\zeta$ of WM. Some views about these parameters are included as follows:

- The probability of crossover $\left(p_{c}\right)$ gives us an expected number $\left(p_{c} \times\right.$ pop_size $)$ of chromosomes which undergo the crossover operation in a generation. When $p_{c}=1$, all chromosomes in a generation will undergo the crossover operation.

- Increasing the probability of mutation $\left(p_{m}\right)$ tends to transform the genetic search into a random search. This probability gives us an expected number $\left(p_{m} \times\right.$ pop_size $\times$ no_vars $)$ of genes that undergo the mutation. When $p_{m}=1$, all genes will mutate. The value of $p_{m}$ depends on the desired number of genes that undergo the mutation operation. 
- Increasing the population size will increase the diversity of the search space, and reduce the probability that GA will prematurely converge to a local optimum. However, it also increases the time required for the population to converge to the optimal region in the search space.

- Changing the value of the weight $w_{a}$ in the average-bounded crossover will change the characteristics of the average crossover operations. It is chosen by trial and error, which depends on the kind of the optimisation problem. As the value of $w_{a}$ tends to 1 , the offspring tends to be the average of the selected parents. As the value of $w_{a}$ tends to 0 , the offspring tends to be the average of the domain boundary. For many optimisation problems, the value of the weight $w_{a}$ can be set as 0.5 .

- Changing the value of the weight $w_{b}$ in the average-bound crossover will change the characteristics of the bound crossover operations. It is also chosen by trial and error, which depends on the kind of the optimisation problem. A value of $w_{b}$ approaching 1 will make the offspring to be near the selected parents. As the value of $w_{b}$ tends to 0 , the offspring will become near the domain boundary.

- Changing the parameter $\zeta$ will change the characteristics of the monotonic increasing function of the wavelet mutation. The dilation parameter $a$ will take a value so as to perform fine-tuning faster as $\zeta$ is increasing. It is chosen by trial and error, which depends on the kind of the optimisation problem. When $\zeta$ becomes larger, the decreasing speed of the step size $(\delta$ ) of the mutation becomes faster. In general, if the optimisation problem is smooth and symmetric, the searching algorithm is easier to find the solution and process the fine-tuning in early iteration. Thus, a larger value of $\zeta$ can be used to increase the step size of the early mutation. More details about the sensitivity of $\zeta$ to WM will be discussed in the next section.

\section{EXPERIMENTAL STUDIES AND ANALYSIS}

\section{A. Benchmark test function}

A suite of 18 benchmark test functions [6, 8, 24, 30] are used to test the performance of the RCGA with the proposed genetic operations. Many different kinds of optimization problems are covered by these benchmark test functions. They are divided into three categories: unimodal functions, multimodal functions with only a few local minima, and multimodal functions with many local minima. The 18 benchmark test functions are detailed in Appendix A. They can test 
the searching ability of the proposed searching algorithm comprehensively. To avoid the proposed crossover operation introducing a strong bias to the optimal location at $\left(\mathbf{p}_{\max }+\mathbf{p}_{\text {min }}\right) / 2$, the ranges of the domain boundary for some test functions are set different from those in [6, 8, 24, 30]. Functions $f_{1}$ to $f_{7}$ are unimodal functions. Functions $f_{8}$ to $f_{13}$ are multimodal functions with only a few local minima. Functions $f_{14}$ to $f_{18}$ are multimodal functions with many local minima.

\section{B. Experimental setup}

The crossover operation for comparison is the UNDXBXover, which consists of two published crossover operations: Unimodal normal distribution crossover (UNDX) [12, 22] and Blend crossover (BLX- $\alpha$ ) [7]. The details of these two crossovers are shown in Appendix B and Appendix C respectively. The mutation operation for comparison is the non-uniform mutation (NUM) [19, 21]. The details of NUM are shown in Appendix D. The simulation conditions are described as follows.

- The shape parameter of NUM: It is chosen by trial and error through experiments for good performance for all functions.

- The parameters $\zeta$ of WM: It is chosen by trial and error through experiments for good performance for all functions.

- The weight of the $\mathrm{ABX} w_{a}: 0.5$ for all functions.

- The weight of the ABX $w_{b}: 0.5$ for $f_{1}$ to $f_{8}$ and $f_{15}$ to $f_{17} ; 1.0$ for. $f_{9}$ to $f_{14}$, and $f_{18}$.

- Population size: 100.

- Number of runs: 50.

- $\quad$ Selection operation: Normalized geometric ranking [10].

- The probability of selecting the best chromosome [10]: 0.08.

- Crossover operation: For UNDX, the parameters $\beta$ and $\mu$ are set at 1 and 0.35 respectively; for BLX- $\alpha$, the parameter $\alpha$ is set at 0.336 [26].

- $\quad$ Probability of crossover $p_{c}: 0.8$.

- $\quad$ Probability of mutation $p_{m}: 0.5$ for $f_{1}$ to $f_{6}$ and $f_{14}$ to $f_{18} ; 0.8$ for $f_{7}$ to $f_{13}$.

- Initial population: It is generated uniformly at random.

In this paper, RCGA with Avergae-Bound Crossover and Wavelet Mutation (ABX+WM), RCGA with Avergae-Bound Crossover and Non-Uniform Mutation (ABX+NUM), RCGA with Unimodal Normal Distribution and Blend Crossover and Wavelet Mutation, (UNDXBXover+WM), and RCGA with Unimodal Normal Distribution and Blend crossover and Non-Uniform Mutation (UNDXBXover+NUM) are used to test the benchmark test functions. 


\section{Experiment results}

\section{Unimodel Functions}

Functions $f_{1}$ to $f_{6}$ are unimodal functions. The experiment results in terms of the mean cost value, best cost value, standard deviation, and the $t$-test value for $f_{1}$ to $f_{6}$ are tabulated in Table. I. The comparison between different genetic operations on $f_{1}$ to $f_{6}$ is shown in Fig. 6 . The $t$-test is a statistical method to evaluate the significant difference between two algorithms. The $t$ value will be negative if the first algorithm is better than the second, and positive if it is poorer. When the $t$-value is smaller than -1.645 (degree of freedom $=49$ ), there is a significant difference between the two algorithms with a $95 \%$ confidence level. Function $f_{1}$ is a sphere model which is probably the most widely used test function. It is smooth and symmetric. The performance on this function is a measure of the convergence rate of a searching algorithm. For $f_{1}$, the results in terms of the mean and the best cost value of ABX with WM or NUM are better than those of the corresponding UNDXBXover. Comparing ABX with WM to UNDXBXover with WM, the mean cost value is 2.5 times better. A much smaller standard deviation is given by the $\mathrm{ABX}+\mathrm{WM}$, which means the solution is more stable. Comparing the mutation operations WM and NUM, the proposed WM is more effective than NUM in term of the cost value and standard deviation. Both the solution quality and stability offered by WM are better than those offered by NUM. In addition, the $t$ value of -10.62 implies that the improved genetic operations (AveXover with WM) are better than the conventional genetic operations (UNDXBXover with NUM). In Fig. 6, ABX with WM displays a faster convergence rate than UNDXBXover with NUM thanks to its better searching ability. It reaches approximately 0.01 in around 250 times of iteration, while it is about 3.0 for UNDXBXover with NUM. Function $f_{2}$ is a generalized Rosenbrock's function which is strongly non-separable and the optimum is located in a very narrow ridge. The tip of the ridge is very sharp, and it runs around a parabola. Algorithms that are unable to discover good searching directions will perform poorly in this problem. The proposed genetic operations (ABX with WM) outperforms the UNDXBXover with NUM. The $t$ value is -313.3 . Although the best cost values on using WM with different crossover operations are a bit worse than those on using NUM, the mean value, standard deviation and convergence rate offered by WM are better. Function $f_{3}$ is a step function that is a representative of flat surfaces. Flat surfaces are obstacles for optimization algorithms because they do not give any information about the search direction. Unless the algorithm has a variable step size, it can get stuck in one of the flat surfaces. UNDXBXover performs poorly for $f_{3}$ because it mainly searches in a small local neighbourhood, but the flat 
surfaces do not give any searching direction for UNDXBXover. On the other hand, the proposed $\mathrm{ABX}$ is good for $f_{3}$ because it can generate longer jump than UNDXBXover. Comparing WM to NUM with UNDXBXover, the former also gives a better solution. Function $f_{4}$ is a quartic function, which is a simple unimodal function padded with noise. The Gaussian noise causes the algorithm never getting the same value at the same point. Many algorithms that do not do well in this function are due to the noisy data. In this function, the mean cost value, best cost value, standard deviation and the convergence rate brought by the proposed $A B X$ and WM are significantly better than the conventional genetic operations. Function $f_{5}$ is the Schwefel's problem 2.21, function $f_{6}$ is the Schwefel's problem 2.22 and function $f_{7}$ is the Eason's function. In these problems, the performance on using the proposed crossover $\mathrm{ABX}$ and mutation WM is better than that on using the UNDXBXover and NUM. The rapid convergence of the proposed genetic operations shown in Fig. 6 supports our argument. In short, the proposed genetic operations (ABX and WM) are good to tackle unimodal functions/problems when compared with the conventional genetic operations (UNDXBXover and NUM). Both the solution quality and stability are satisfactory.

\section{Multimodel functions with a few local minima}

Functions $f_{8}$ to $f_{13}$ are multimodal functions with only a few local minima. The experimental results for $f_{8}$ to $f_{13}$ are tabulated in Table II. Fig. 7 shows the average values for $f_{8}$ to $f_{13}$. Among these functions, five of them $\left(f_{8}, f_{10}-f_{13}\right)$ do not show statistically significant differences for different genetic operations. They all reach or get near to the global optima. For the function $f_{9}$, we obtain statistically different results from the proposed genetic operations and the conventional genetic operations. The proposed ABX performs better than the UNDXBXover in terms of the mean, best value, standard deviation and the convergence rate. In addition, the results offered by WM are better than those by NUM in terms of the mean and the best cost values. Furthermore, WM gives a faster convergence rate.

\section{Multimodel functions with many local minima}

Functions $f_{14}$ to $f_{18}$ are multimodal functions with many local minima, and the dimension of each function is comparatively larger than that of $f_{8}$ to $f_{13}$. The dimension of these functions is 30. The experimental results for $f_{14}$ to $f_{18}$ are tabulated in Table III. The comparison between different genetic operations is shown in Fig. 8. It can be seen from Table III that the mean results and the best results offered by the proposed genetic operations (ABX and WM) are better than 
those offered by the conventional genetic operations (UNDXBXover and NUM). Also, they have smaller standard deviations. Therefore, in terms of the solution quality and stability, the proposed genetic operations are better than the conventional operations. In addition, the $t$-test value of all functions is smaller than -1.645 . Therefore, the proposed genetic operations are significantly better than the conventional operations for solving the optimization problems. From Fig. 8, we can see that the convergence rate offered by the proposed genetic operations is better than that offered by the conventional genetic operations.

\section{The searching ability of wavelet mutation}

In this section, we give an analysis based on experimental results to illustrate that the searching ability of WM is better than that of NUM. The experimental settings are the same as before, except the probability of crossover is set at 0 and the probability of mutation is set at 1 . By using this setting, no chromosomes will undergo the crossover operation, and all genes in the population will mutate under the mutation operation. Hence, the searching ability of the mutation operation can be evaluated. The experimental results on using WM and NUM for $f_{1}$ to $f_{18}$ (except $f_{3}$ and $f_{7}$ ) without crossover operation are summarized in Table IV. The comparison between WM and NUM is given in Fig. 9 and Fig. 10. Function $f_{3}$ and $f_{7}$ are not included in this experiment because they do not perform well with mutation operation only. As seen from Table IV, the average performance of WM is better than NUM. WM gives smaller standard deviations of results for all test functions than NUM, and hence the solution stability offered by WM is better. From Fig. 9 and Fig. 10, the convergence of WM is found faster than that of NUM. In conclusion, the searching ability of WM is better than NUM.

\section{E. Sensitivity of the parameter for wavelet mutation}

The mean cost values offered by WM using different shape parameter $\zeta$ for all test functions are tabulated in Table V. As can be seen from the table, all functions are tested by using $\zeta=0.2, \zeta=0.5, \zeta=1, \zeta=2$, and $\zeta=5$. If the optimization problem needs a more significant mutation to reach the optimal point, a smaller $\zeta$ should be given. Conversely, if the RCGA needs to perform the fine-tuning faster, a larger $\zeta$ should be used. For example, $f_{1}$ is a sphere model which is smooth and symmetric. Searching algorithms are fast to jump to the area near the global optimum and then perform fine-tuning. Therefore, a larger $\zeta$ is set $(\zeta=5)$ so that the RCGA will go to perform fine-tuning faster. On the other hand, $\zeta$ is set as 0.2 for $f_{13}$ when the mutation operation is playing a significant role at the later stage. In some cases, $\zeta$ 's value is not very critical, e.g. $f_{3}$ and $f_{11}$. For $f_{3}$, the mean cost value for different $\zeta$ is the same. We say that the best 
performance is obtained when $\zeta=0.5$ because the standard deviation of the RCGA for $\zeta=0.5$ is the smallest. However, in some cases, the parameter $\zeta$ is so sensitive as to affect the performance of the searching, e.g. $f_{1}$ and $f_{16}$. In conclusion, no formal method is available to choose the parameter $\zeta$; it depends on the characteristics of the optimization problems.

\section{F. Sensitivity of the initial range of variables}

Additional experiments are carried out to test the sensitivity of the initial range of the variables to the RCGA with the improved genetic operations. The settings of these experiments are exactly the same as before (section III B). The experiment results for $f_{4}$ are tabulated in Table VI. Fig. 11 shows the results for different genetic operations on $f_{4}$. The initial population is generated uniformly at random in the ranges of $-2.56 \leq x_{i} \leq 5.12$ (twice the original range), $-6.4 \leq x_{i} \leq 12.8$ (5 times of the original range), $-12.8 \leq x_{i} \leq 25.6$ (10 times of the original range), and $-25.6 \leq x_{i} \leq 51.2$ (20 times of the original range), making the average distance to the global optimum increasingly large. The enlarged searching space is expected to make the problem more difficult to solve. As can be seen from the table and the figures, the mean cost values offered by the proposed genetic operations are better than those by the conventional genetic operations. From Fig. 11, ABX and WM offer faster convergence than UNDXBXover and NUM. In addition, ABX and WM give smaller standard deviation for all initial ranges than UNDXBXover and NUM. Hence, the solution quality is more stable. Two more test functions are then used to test the sensitivity to the initial range of variables. The experiment results for $f_{7}$ and $f_{16}$ are tabulated in Table VII to VIII respectively. Fig. 12 and Fig. 13 show the results for different genetic operations on $f_{7}$ and $f_{16}$ respectively. In these tables and figures, the results of the improved genetic operations in terms of the mean cost value, convergence rate, and standard deviation are better than those of the conventional algorithms.

\section{APPLICATION EXAMPLES}

Application examples on economic load dispatch and tuning of associative memory are given in this section.

\section{A. Economic load dispatch}

In a power system, minimizing the operation cost is important. Economic load dispatch (ELD) is a method to schedule power generator outputs with respect to the load demands, and to operate a power system economically. The input-output characteristics of modern generators are 
nonlinear by nature because of the valve-point loadings and rate limits. The problem of ELD is multimodal, discontinuous and highly nonlinear. RCGAs had been employed to solve the ELD problems [2, 27].

\section{Mathematic modelling of economic load dispatch with valve-point loading}

The economic load dispatch with valve-point loading problem can be formulated into the following objective function:

$$
\operatorname{Min} \sum_{i=1}^{n} C_{i}\left(P_{L_{i}}\right) \text {, }
$$

where $C_{i}\left(P_{L_{i}}\right)$ is the operation fuel cost of generator $i$, and $n$ denotes the number of generators. The problem is subject to a balance constraint and generating capacity constraints as follows:

$$
\begin{aligned}
& D=\sum_{i=1}^{n} P_{L_{i}}-P_{\text {Loss }}, \\
& P_{L_{i, \min }} \leq P_{L_{i}} \leq P_{L_{i, \max }}, i=1,2, \ldots, n .
\end{aligned}
$$

where $D$ is the load demand, $P_{L_{i}}$ is the output power of the $i$-th generator, $P_{\text {Loss }}$ is the transmission loss, $P_{L_{i, \max }}$ and $P_{L_{i, \min }}$ are the maximum and minimum output powers of the $i$-th generator respectively. The operation fuel cost function with valve-point loadings of the generators is given by,

$$
C_{i}\left(P_{L_{i}}\right)=a_{i} P_{L_{i}}^{2}+b_{i} P_{L_{i}}+C_{i}+\left|e_{i} \times \sin \left(f_{i} \times\left(P_{L_{i, \min }}-P_{L_{i}}\right)\right)\right|,
$$

where $a_{i}, b_{i}$, and $c_{i}$ are coefficients of the cost curve of the $i$-th generator, $e_{i}$ and $f_{i}$ are coefficients of the valve-point loadings. (The generating units with multivalve steam turbines exhibit a great variation in the fuel-cost functions. The valve-point effects introduce ripples in the heat-rate curves.)

RCGA can be used to solve the economic load dispatch problem. The chromosomes $\mathbf{p}$ is defined as follows:

$$
\mathbf{p}=\left[\begin{array}{lllll}
P_{L_{1}} & P_{L_{2}} & P_{L_{3}} & \cdots & P_{L_{n-1}}
\end{array}\right],
$$

From (22), we have,

$$
P_{L_{n}}=D-\sum_{i=1}^{n-1} P_{L_{i}}+P_{\text {Loss }} \text {. }
$$

In this paper, the power loss is not considered. Therefore,

$$
P_{L_{n}}=D-\sum_{i=1}^{n-1} P_{L_{i}}
$$


To ensure $P_{L_{n}}$ falls within the range $\left[P_{L_{n, \min }}, P_{L_{n, \max }}\right]$, the following conditions are considered:

$$
\begin{aligned}
& \text { if } P_{L_{n}}>P_{L_{n, \text { max }}}\left\{\begin{array}{l}
P_{L_{1} \text { New }}=P_{L_{1}}+\left(P_{L_{n, \text { max }}}-P_{L_{n}}\right) \\
P_{L_{n}}=P_{L_{n, \text { max }}}
\end{array}\right. \\
& \text { if } P_{L_{n}}<P_{L_{n, \text { min }}}\left\{\begin{array}{l}
P_{L_{1} \text { New }}=P_{L_{1}}-\left(P_{L_{n}}-P_{L_{n, \text { min }}}\right) \\
P_{L_{n}}=P_{L_{n, \text { min }}}
\end{array}\right.
\end{aligned}
$$

It should be noted from (28) and (29) that if the value of $P_{L_{1}}$ is also outside the constraint boundaries. The exceeding portion of the power will further be shared by other generators in order to make sure that all generators' output power is within the safety range. Referring to (21), the fitness function for this ELD problem is defined as:

fitness $=-\sum_{i=1}^{n} C_{i}\left(P_{L_{i}}\right)$,

where $C_{i}\left(P_{L_{i}}\right)$ is defined in (24). The objective is to maximize the fitness function (30).

\section{Case Study}

The RCGA with the proposed genetic operations and the RCGA with the conventional genetic operations are applied to a 40-generator system, which was adopted as an example in [2]. The system is a very large one with nonlinearities. The data of the units for this example with valve-point loadings are tabulated in Table IX. The load demand $(D)$ is 10500MW. For comparison purpose, RCGA with ABX and WM, RCGA with ABX and NUM, RCGA with UNDXBXover and WM, and RCGA with UNDXBXover and NUM are used to solve the ELD problem. The population size used for all RCGAs is 100. All the simulation results are averaged ones out of 50 runs. For the proposed $\mathrm{ABX}$, the parameters $w_{a}$ and $\mathrm{w}_{b}$ are set at 0.5. For the UNDXBXover, the parameters $\beta, \mu$, and $\alpha$ are set at $1,0.35$, and 0.336 respectively. For the proposed mutation WM, the parameter $\zeta$ is set at 1 . For the NUM, the shape parameter is set at 1 . The probabilities of crossover and mutation for all approaches are set at 0.6 by trial and error. For all approaches, the number of iteration is 1000. The statistical results are shown in Table X and Fig. 14. It can be seen that the RCGA with the proposed ABX and WM performs better than other RCGAs with conventional genetic operations (UNDXBXover and NUM) in terms of cost, $t$ value, and standard deviation. Both the solution quality and stability are good. The average cost is $\$ 122811.41$ and the best (minimum) cost is $\$ 121915.93$. The optimal dispatch solution is summarized in Table XI.

\section{B. Tuning associative memory}


Learning or training is one of the important issues of neural networks. The learning process aims to find a set of optimal network parameters. The widely-used gradient methods [28, 31], such as MRI, MRII, MRIII rules, and back-propagation techniques, adjust the network parameters based on the gradient information of the fitness function in order to reduce the mean square error over all input patterns. One major weakness of the gradient methods is that the derivative information of the fitness function has to be known, meaning that the fitness function has to be continuous. Also, the learning process is easily trapped in a local optimum, especially when the problems are multimodal and the learning rules are network structure dependent. To tackle this problem, the real-code genetic algorithm (RCGA) [5, 19, 25], was proposed for the optimization problem in a large, complex, non-differentiable and multimodal domain [29]. RCGA is a good training algorithm for neural or neural-fuzzy networks [15-16]. The same RCGA can be used to train many different networks regardless of whether they are feed-forward one, recurrent one, associative memory or of other structure types. This generally saves a lot of human efforts in developing training algorithms for different types of networks.

Associative memory is one type of neural network that maps its input vector into itself. Thus, the desired output vector is its input vector. 50 input vectors are used for the learning. The function of the associative memory is given by:

$$
y_{k}(t)=\sum_{j=1}^{10} w_{j k} z_{j}(t), k=1,2, \ldots, 10
$$

where $z(t)$ is the input vector and $w_{j k}$ is the weight of the link between the $i$-th input and the $k$-th output. The objective is to minimize the mean square error (MSE), which is defined as follows:

MSE $=\frac{\sum_{k=1}^{10} \sum_{t=1}^{50}\left(z_{k}(t)-y_{k}(t)\right)^{2}}{10 \times 50}$

The initial range of the weight $w_{j k}$ is from -2 to 2 . For comparison purpose, RCGA with ABX and WM, RCGA with ABX and NUM, RCGA with UNDXBXover and WM, and RCGA with UNDXBXover and NUM are used to solve this problem. The population size used for all RCGAs is 100. All the simulation results are averaged ones out of 50 runs. For the proposed $A B X$, the parameters $w_{a}$ and $w_{b}$ are set at 0.5 and 1 respectively. For the UNDXBXover, the parameters $\beta$, $\mu$, and $\alpha$ are set at $1,0.35$, and 0.336 respectively. For the proposed mutation $\mathrm{WM}$, the parameter $\zeta$ is set at 2. For the NUM, the shape parameter is set at 2 . The probabilities of crossover and mutation for all approaches are set at 0.8 and 0.2 by trial and error. For all approaches, the number of iteration is 2000. The experimental results are tabulated in Table XII, and the comparison between different genetic operations is shown in Fig. 15. As can be seen from the table, the mean and the best cost value offered by $\mathrm{ABX}$ and WM are better. In addition, the smaller standard 
deviation implies a more stable solution. The $t$-value for this function is -24.67 , which is a relatively large figure. In short, the proposed RCGA is good for tuning associative memory.

\section{CONCLUSION}

An RCGA with improved genetic operations (average-bound crossover and wavelet mutation) has been presented. By using the proposed crossover operation, the offspring spreads over the domain so that the probability of reproducing good offspring is increased. In the proposed mutation operation, the wavelet theory is applied. Thanks to the properties of the wavelet, both the solution quality and stability are improved. A suit of benchmark test functions has been used to illustrate the merits of the improved genetic operations. Examples on economic load dispatch and tuning associative memory have also been given.

\section{ACKNOWLEDGEMENT}

The work described in this paper was substantially supported by a grant from the Hong Kong Polytechnic University (PhD Student Account Code: RG9T).

\section{REFERENCES}

[1] Caponetto R., Fortuna L., Nunnari G., Occhipinti L., and Xibilia M.G., "Soft computing for greenhouse climate control,” IEEE Trans., Fuzzy Systems, vol. 8, no. 6, pp. 753-760, Dec. 2000.

[2] Chen P.H. and Chang H.C., "Large-scale economic dispatch by genetic algorithm,” IEEE Trans. Power Syst., vol. 10, pp. 117-124, Feb. 1995.

[3] Daubechies I., “The wavelet transform, time-frequency localization and signal analysis,” IEEE Trans. Information Theory, vol. 36, no.5, pp. 961-1005, Sep. 1990.

[4] Daubechies I., Ten lectures on wavelets. Philadelphia, PA: Society for Industrical and Applied Mathematics, 1992.

[5] Davis L., Handbook of genetic algorithms. NY: Van Nostrand Reinhold, 1991.

[6] De Jong K.A., “An analysis of the behavior of a class of genetic adaptive systems,” Ph.D. Thesis, University of Michigan, Ann Arbor, MI, 1975.

[7] Eshelman L.J. and Schaffer J.D., "Real-coded genetic algorithms and interval-schemata," Foundations of Genetic Algorithms 2, pp. 187-202, 1993.

[8] Goldstein A.A. and Price I.F., “On descent from local minima,” Math. Comput., vol. 25, no. 115, 1971.

[9] Holland J.H., Adaptation in natural and artificial systems. University of Michigan Press, Ann Arbor, MI, 1975. 
[10] Joines J. and Houck C., "On the use of non-stationary penalty functions to solve constrained optimization problems with genetic algorithm,” in Proc. 1994 Int. Symp. Evolutionary Computation, Ordando, 1994, pp. 579-584.

[11] Juidette H. and Youlal H., "Fuzzy dynamic path planning using genetic algorithms," Electronics Letters, vol. 36, no. 4, pp. 374-376, Feb. 2000.

[12] Kita H., Ono I., and Kobayashi S., "Theoretical analysis of the unimodal normal distribution crossover for real-coded genetic algorithms," in Proc. of the Congress on Evolutionary Computational (CEC1998), World Congress on Computational Intelligence (WCCI 1998), May 4-9, 1998, pp. 529-534.

[13] Lam H.K., Leung F.H.F., and Tam P.K.S., "Design and stability analysis of fuzzy model based nonlinear controller for nonlinear systems using genetic algorithm,” IEEE Trans. Syst., Man and Cybern, Part B: Cybernetics, vol. 33, no. 2, pp. 250-257, Feb. 2003.

[14] Leung F.H.F., Lam H.K., Ling S.H., and Tam P.K.S., "Optimal and stable fuzzy controllers for nonlinear systems using an improved genetic algorithm," IEEE Trans. Industrial Electronics, vol. 51, no. 1, pp.172-182, Feb. 2004.

[15] Leung F.H.F, Lam H.K., Ling S.H., and Tam P.K.S., "Tuning of the structure and parameters of neural network using an improved genetic algorithm," IEEE Trans. Neural Networks, vol.14, no. 1, pp.79-88, Jan. 2003.

[16] Ling S.H., Leung F.H.F, Lam H.K., and Tam P.K.S., "Short-term electric load forecasting based on a neural fuzzy network," IEEE Trans. Industrial Electronics, vol. 50, no. 6, pp.1305-1316, Dec. 2003.

[17] Liu B.D., Chen C.Y., and Tsao J.Y., "Design of adaptive fuzzy logic controller based on linguistichedge concepts and genetic algorithms,” IEEE Trans. Systems, Man and Cybernetics, Part B, vol. 31 no. 1, pp. 32-53, Feb. 2001.

[18] Mallat S.G., "A theory for multiresolution signal decomposition: the wavelet representation,” IEEE Trans. Pattern analysis and machine intelligence, vol. 11, no.7, pp. 674-693, Jul. 1989.

[19] Michalewicz Z., Genetic Algorithm + Data Structures = Evolution Programs, 2nd extended ed. Springer-Verlag, 1994.

[20] Mühlenkein H. and Schlierkamp-Voosen D., "Predictive models for the breeder genetic algorithm I. continuous parameter optimization,” Evolutionary Computation, vol.1, no.1, pp. 25-49, 1993.

[21] Neubauer A., "A theoretical analysis of the non-uniform mutation operator for the modified genetic algorithm,” in Proc. IEEE Int. Conf. Evolutionary Computation, 1997, Indianapolis, pp. 93-96.

[22] Ono I. and Kobayashi S., "A real-coded genetic algorithm for function optimization using unimodal normal distribution crossover," in Proc. $7^{\text {th }}$ ICGA, 1997, pp. 246-253.

[23] Pham D.T. and Karaboga D., Intelligent Optimization Techniques, Genetic Algorithms, Tabu Search, Simulated Annealing and Neural Networks. Springer, 2000.

[24] Schwefel H.P., Numerical optimization of computer models. Chichester, Wiley \& Sons, 1981.

[25] Srinivas M.and Patnaik L.M., "Genetic algorithms: a survey," IEEE Computer, vol. 27, issue 6, pp. 17-26, June 1994. 
[26] Takahashi M. and Kita H., "A crossover operator using independent component analysis for realcoded genetic algorithms," in Proc. of the Congress on Evolutionary Computation, (CEC2001), 2001, pp.643-638.

[27] Walter D.C. and Sheble G.B., "Genetic algorithm solution of economic dispatch with valve point loading,” IEEE Trans. Power Syst., vol. 8, pp.1325-1332, Aug. 1993.

[28] Widrow B. and Lehr M.A., "30 years of adaptive neural networks: Perceptron, madaline, and backpropagation," Proceedings of the IEEE, vol. 78, no. 9, pp. 1415-1442, Sept. 1990.

[29] Yao X., "Evolving artificial networks," Proceedings of the IEEE, vol. 87, no. 7, pp. 1423-1447, 1999.

[30] Yao X. and Liu Y., "Evolutionary programming made faster," IEEE Trans. Evolutionary Computation, vol. 3, no. 2, pp. 82-102, July 1999.

[31] Zurada J.M., Introduction to Artificial Neural Systems. West Info Access, 1992.

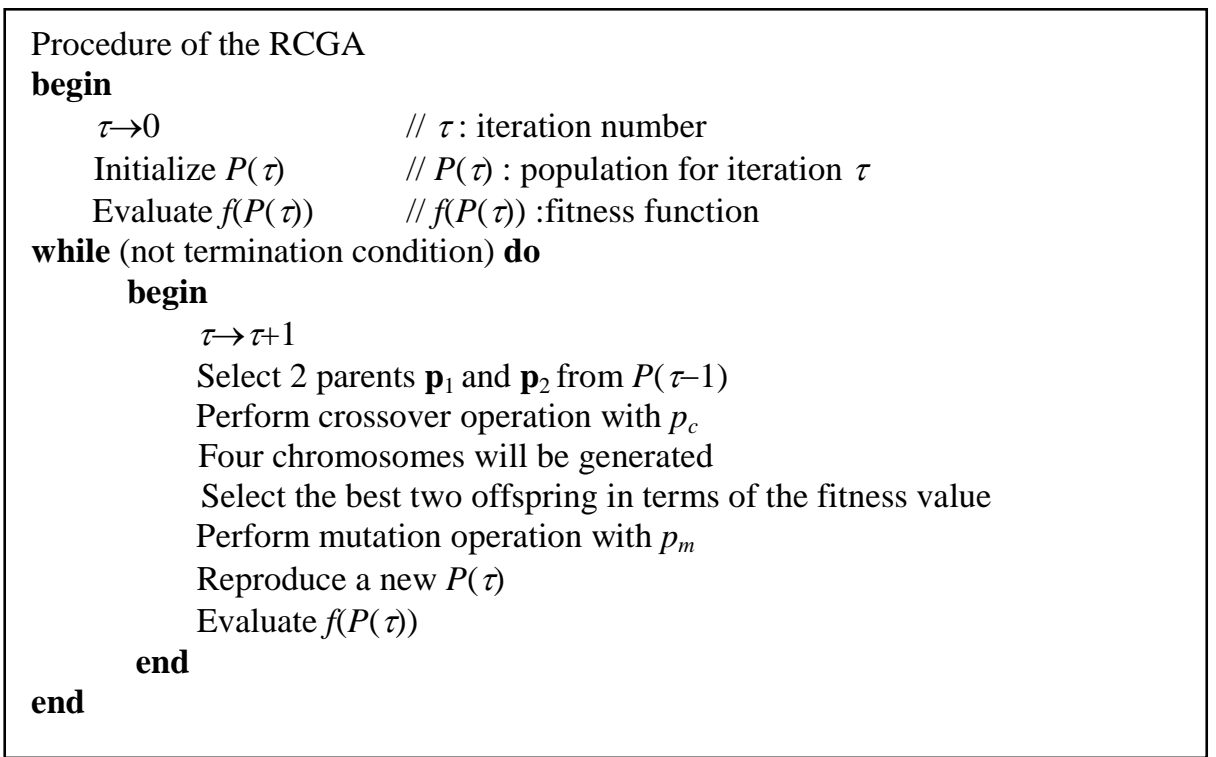

Fig. 1. RCGA process.
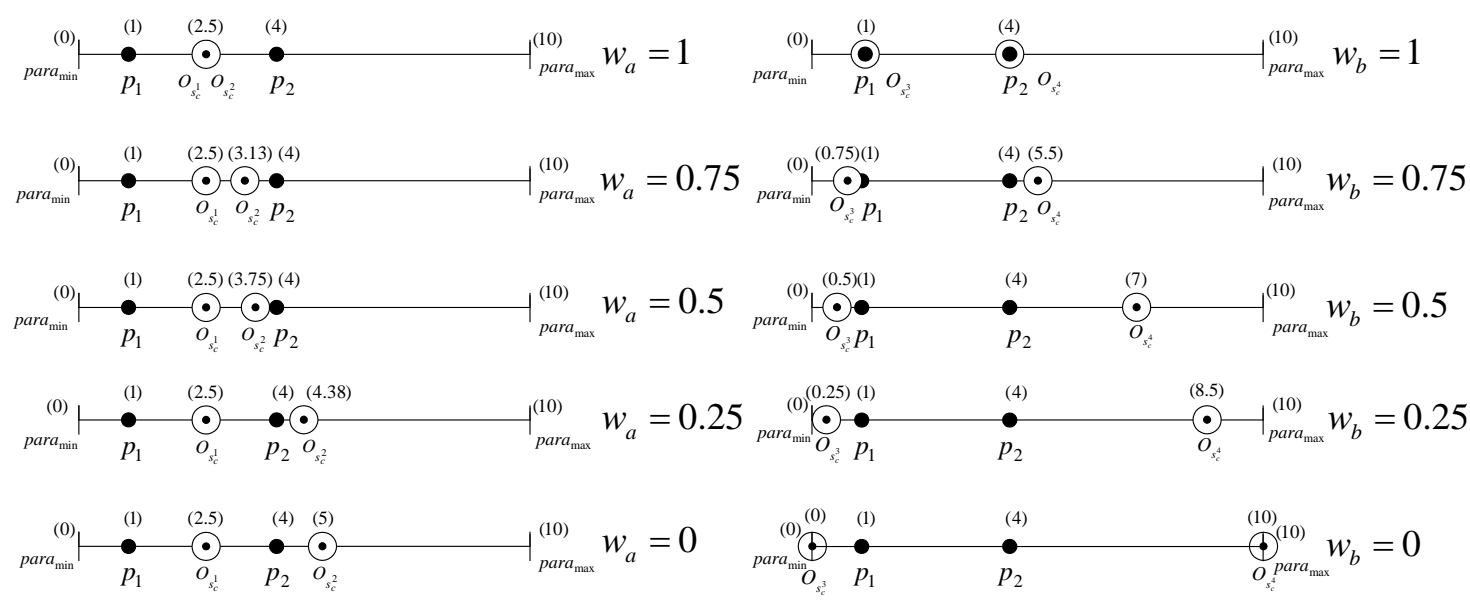

- parent $p_{i}$

offspring $O_{s_{c}^{i}}$

Fig. 2. Parents and offspring under different values of the weights $w_{a}$ and $w_{b}\left(w_{a}, w_{b}=0,0.25,0.5,0.75\right.$ and 1.$)$ 


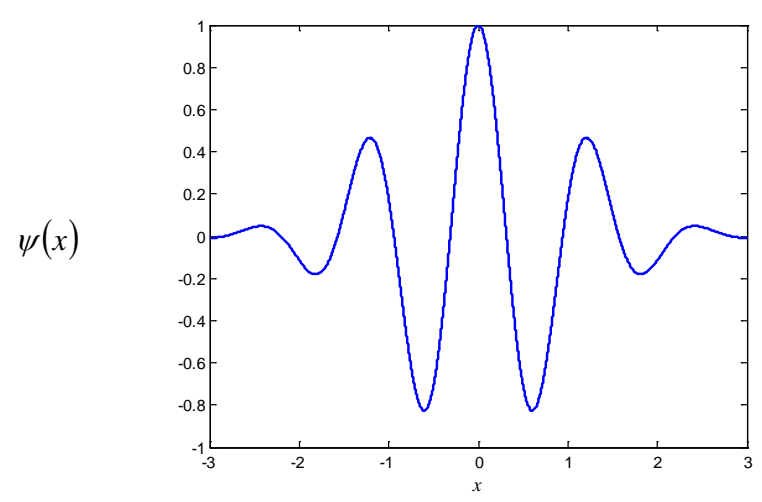

Fig. 3. The Morlet Wavelet.
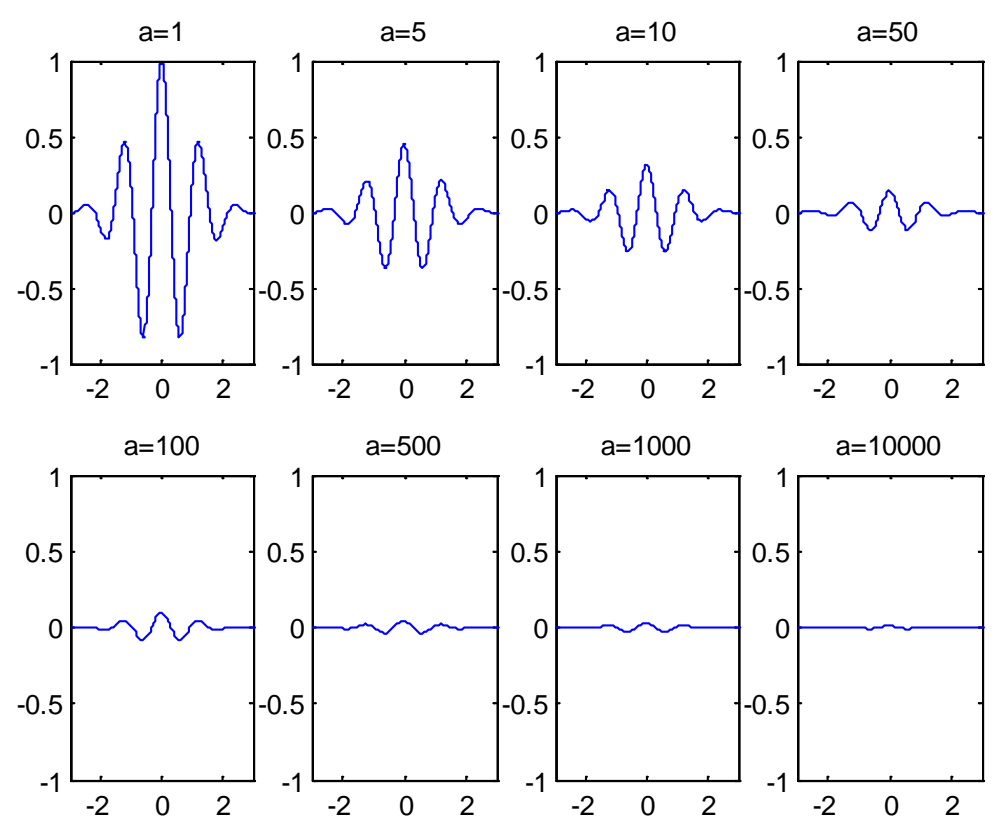

Fig. 4. A Morlet wavelet dilated by different values of the parameter $a$ (x-axis: $x, y$-axis: $\psi_{a, 0}(x)$.)

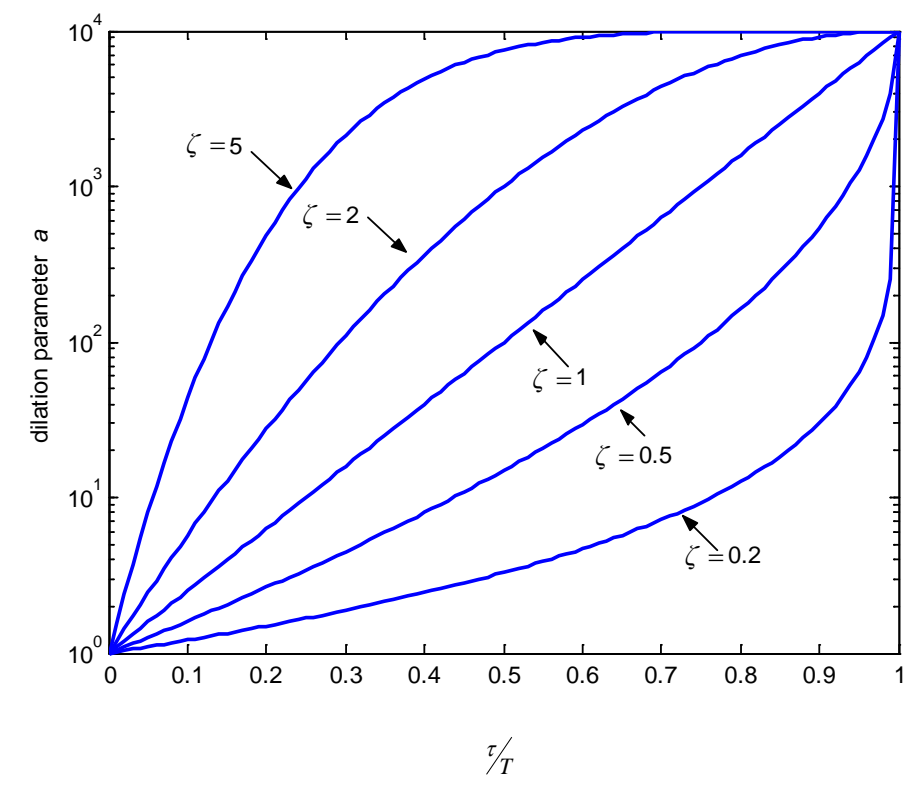

Fig. 5. The effect of the shape parameter $\zeta$ to $a$ with respected to $\tau / T$. 


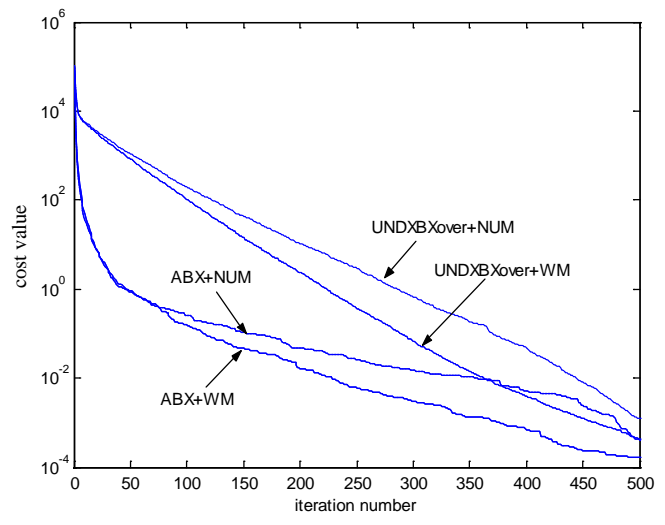

$f_{1}$

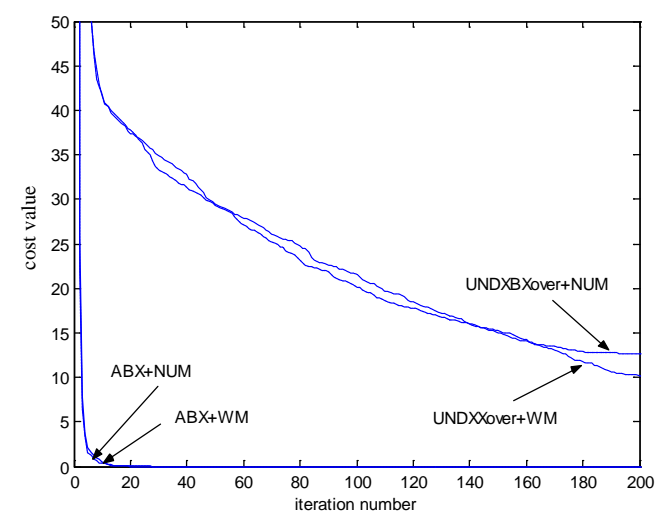

$f_{3}$

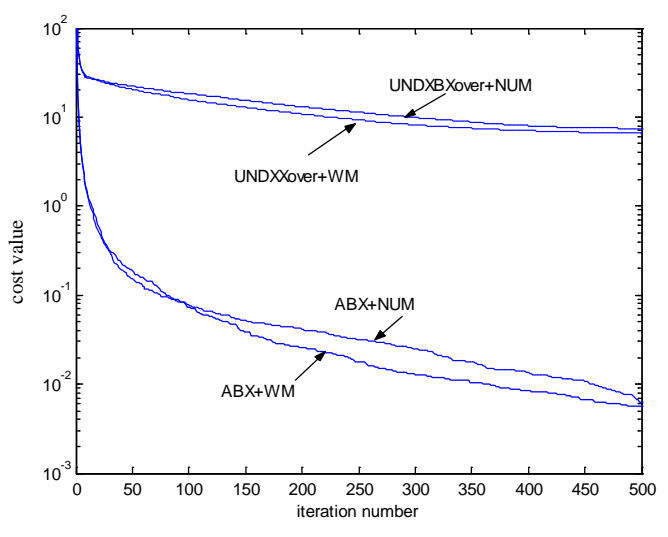

$f_{5}$

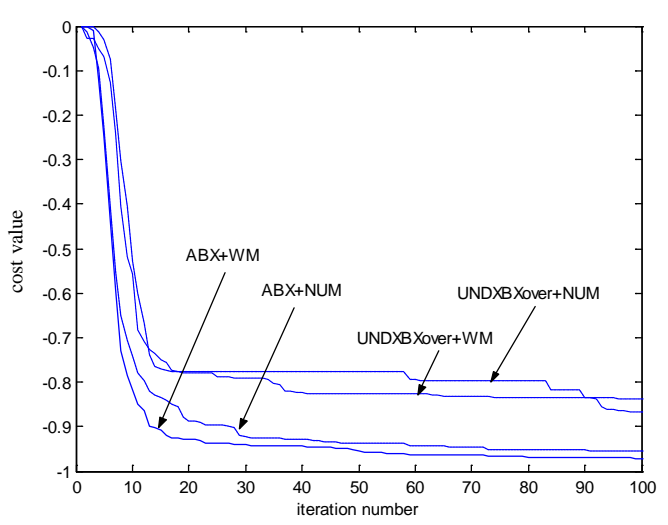

$f_{7}$

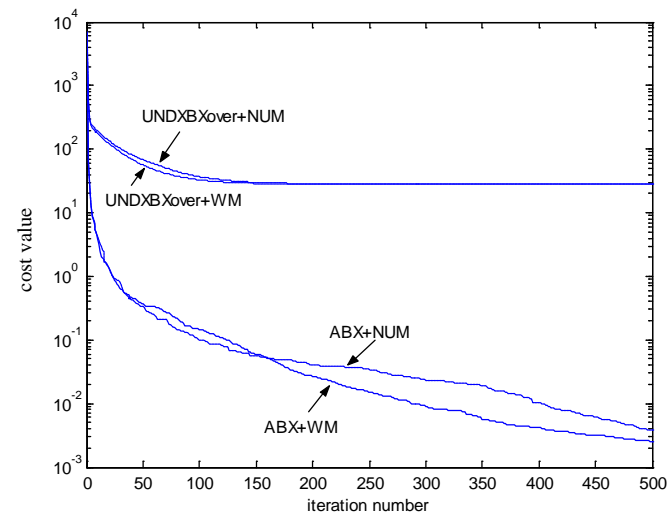

$f_{2}$

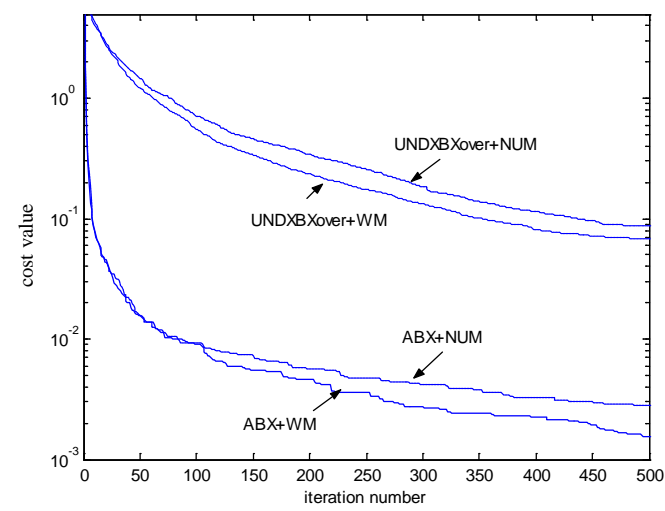

$f_{4}$

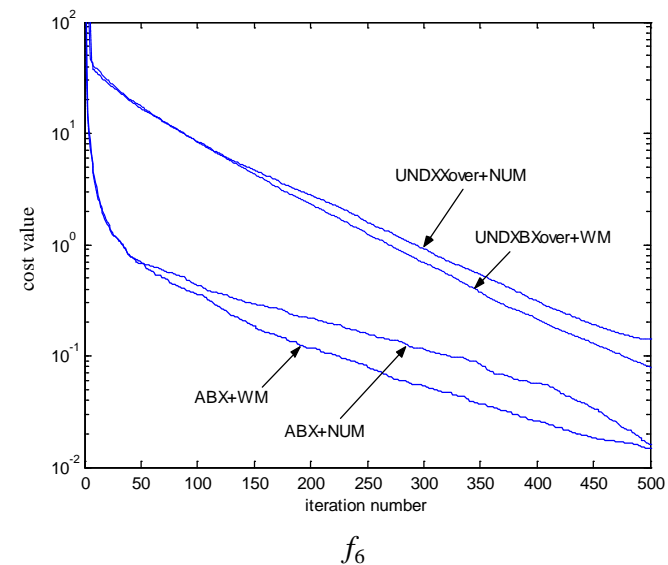

$f_{6}$

Fig. 6. Comparisons between different genetic operations for $f_{1}$ to $f_{7}$. All results are averaged ones over 50 runs. 


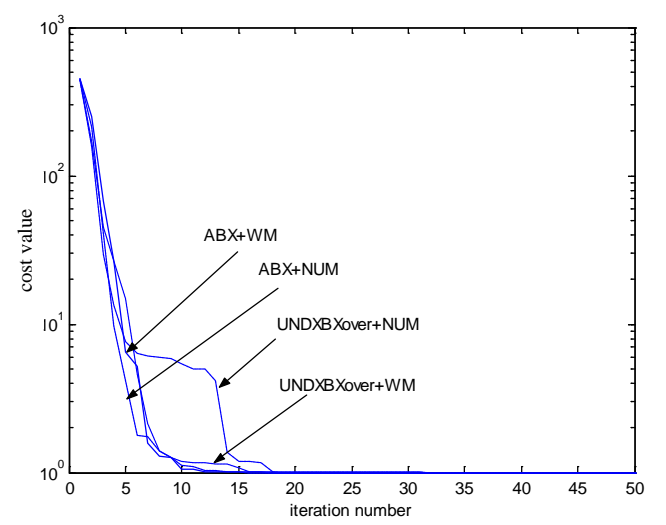

$f_{8}$

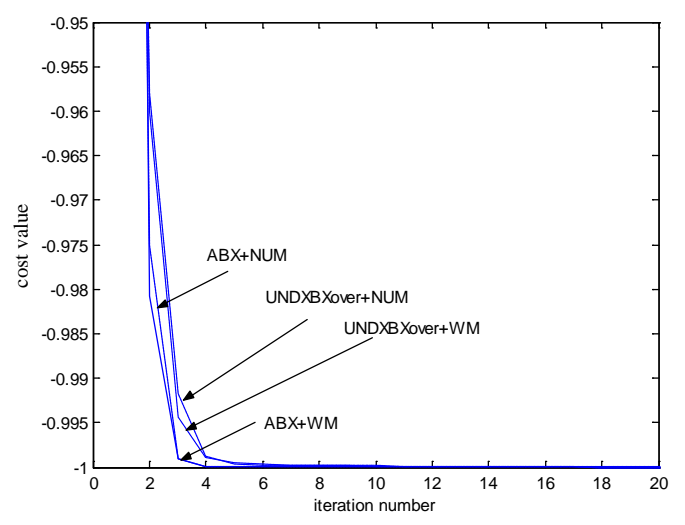

$f_{10}$

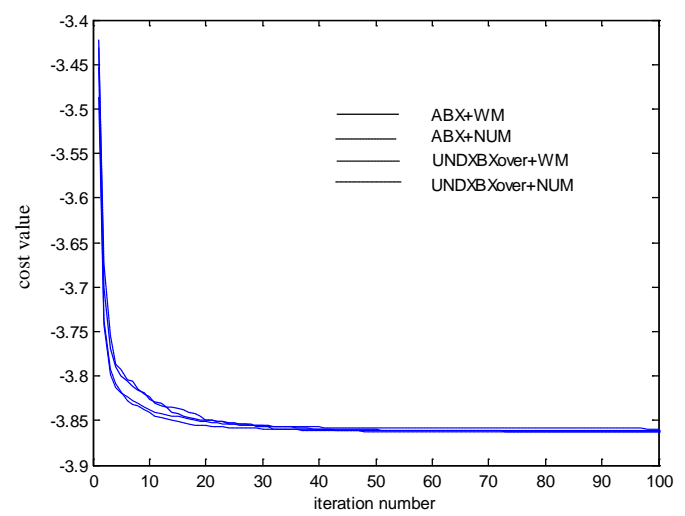

$f_{12}$

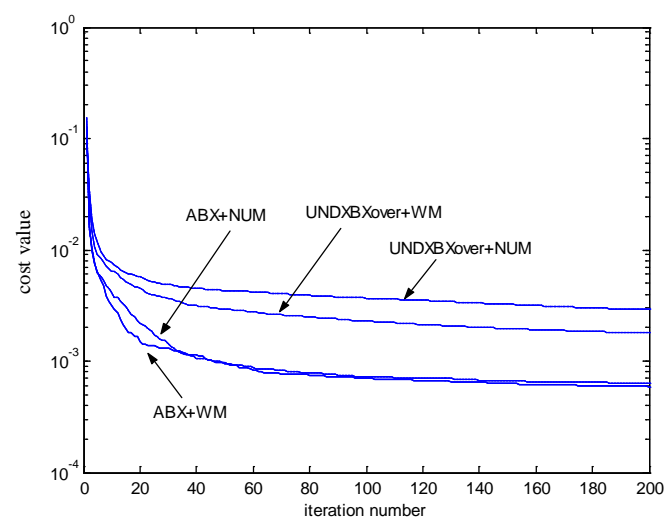

$f_{9}$

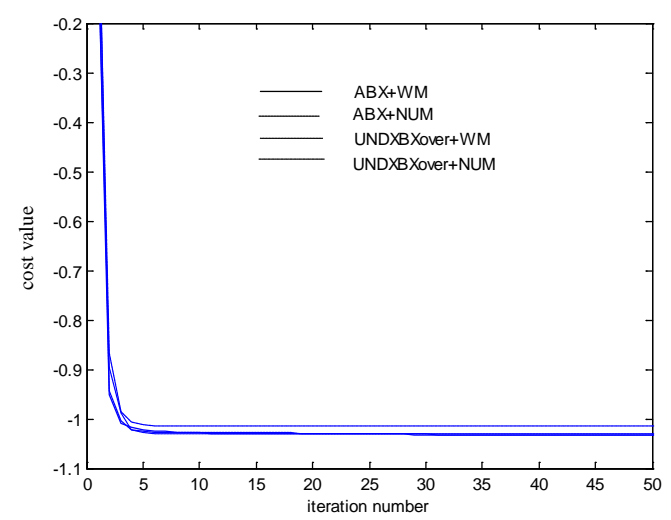

$f_{11}$

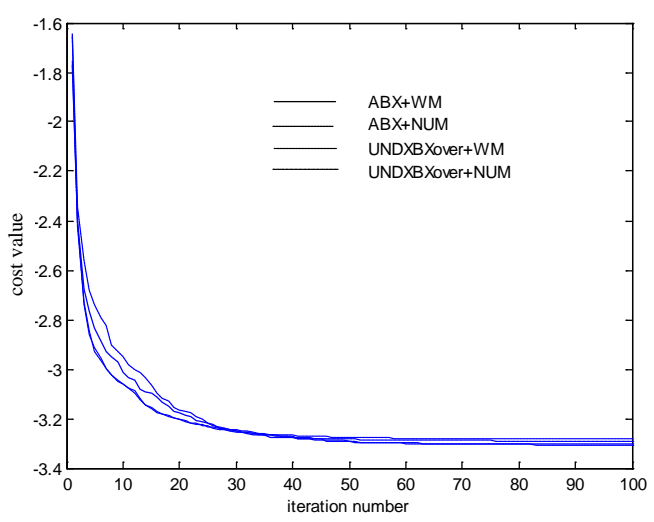

$f_{13}$

Fig. 7. Comparison between different genetic operations for $f_{8}$ to $f_{13}$. All results are averaged ones over 50 runs. 


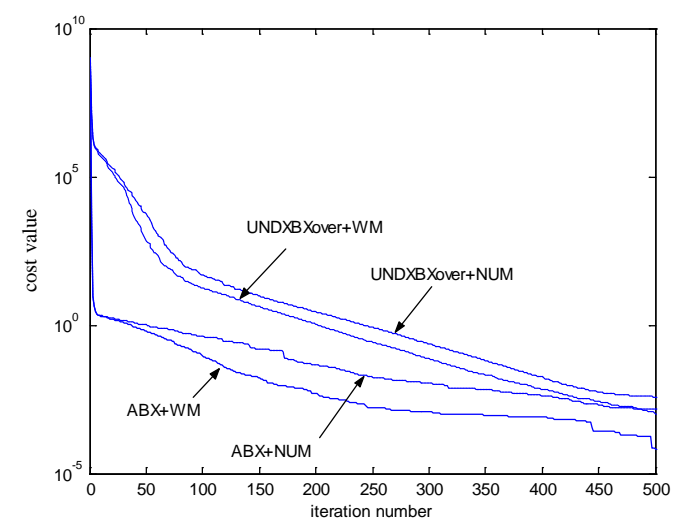

$f_{14}$

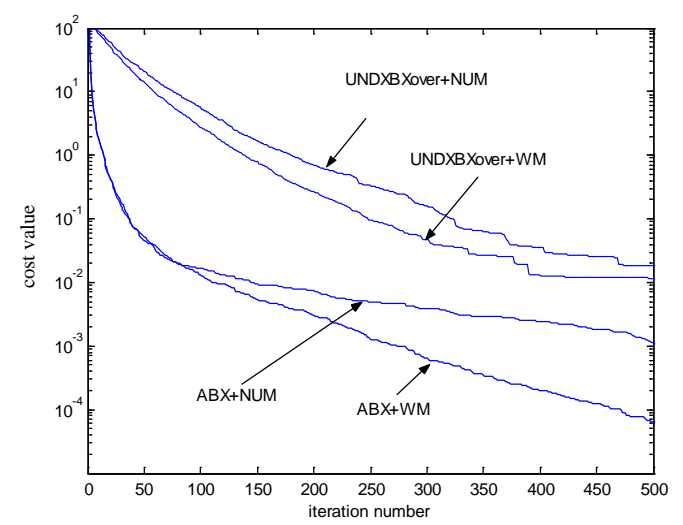

$f_{16}$

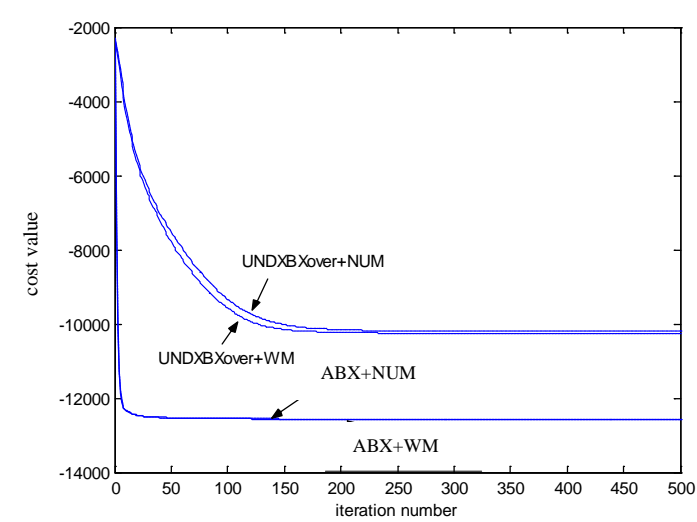

$f_{18}$

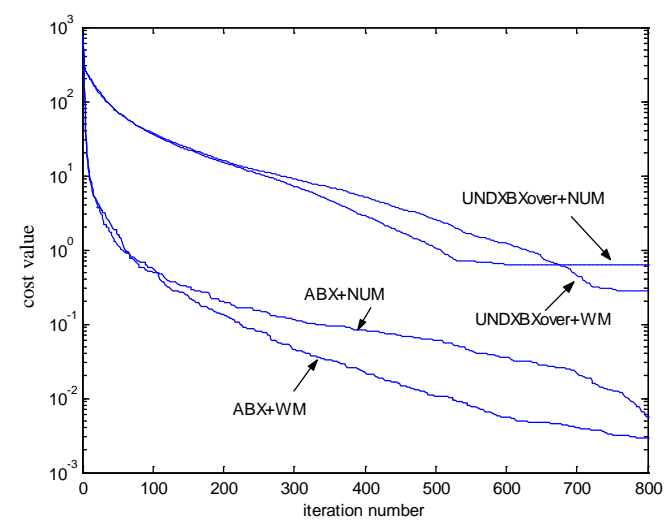

$f_{15}$

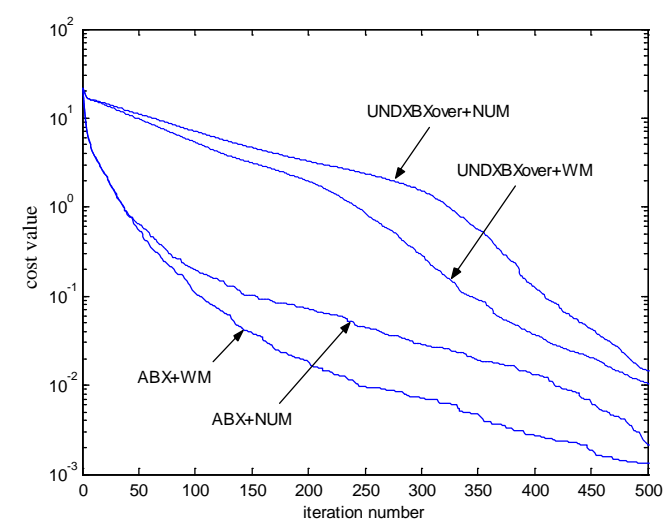

$f_{17}$

Fig. 8. Comparison between different genetic operations for $f_{14}$ to $f_{18}$. All results are averaged ones over 50 runs. 


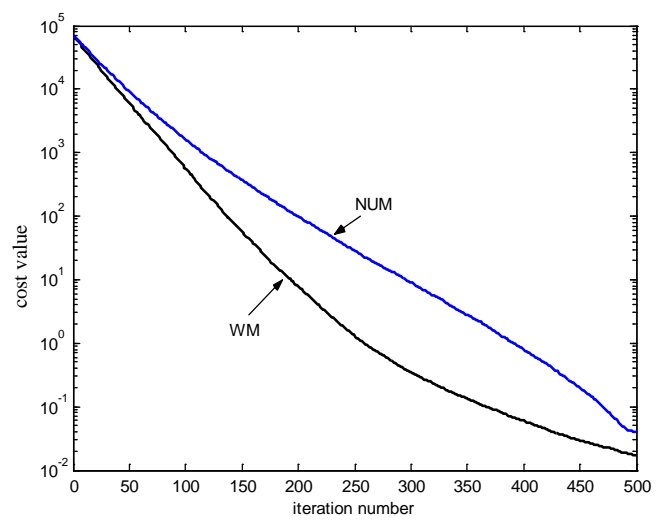

$f_{1}$

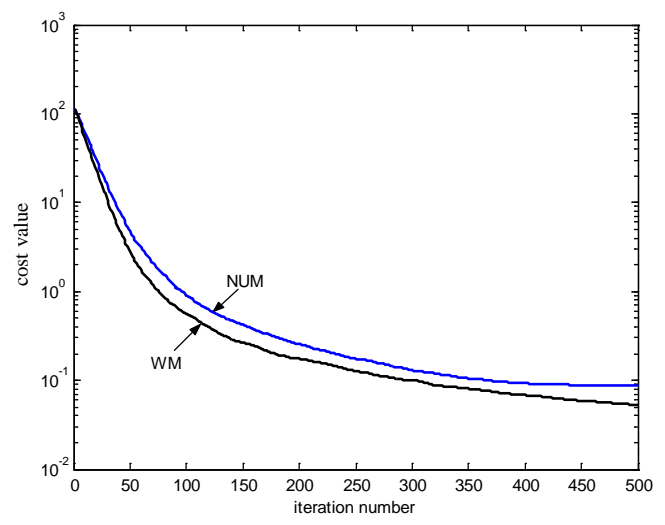

$f_{4}$

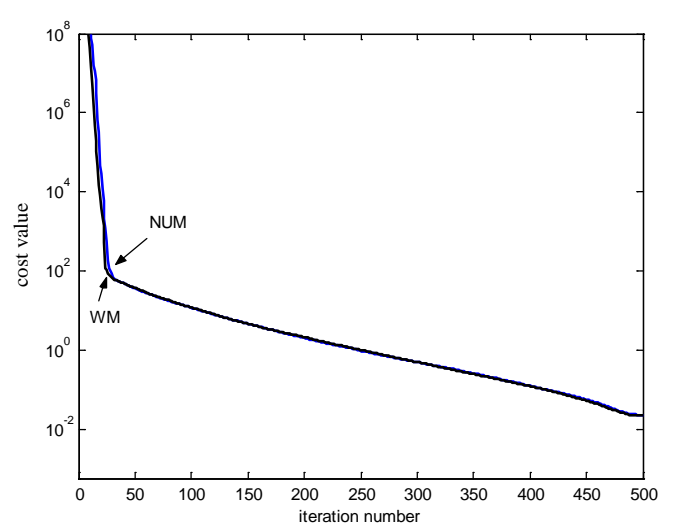

$f_{6}$

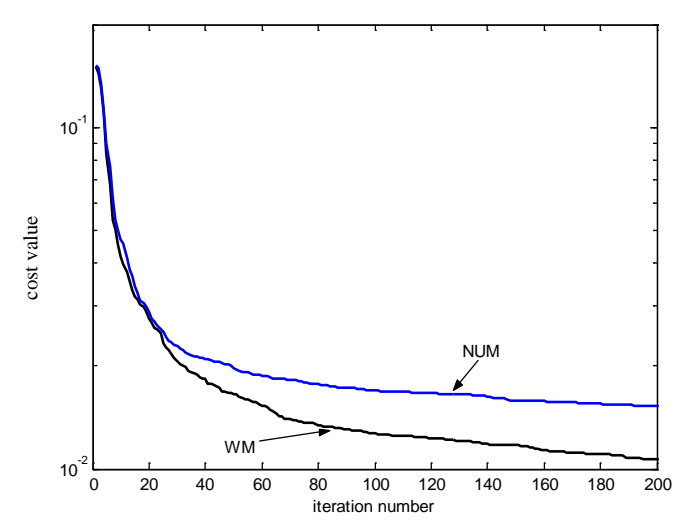

$f_{9}$

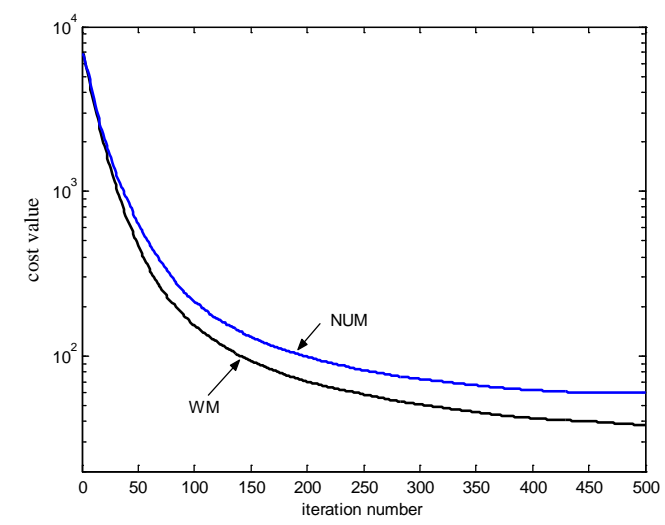

$f_{2}$

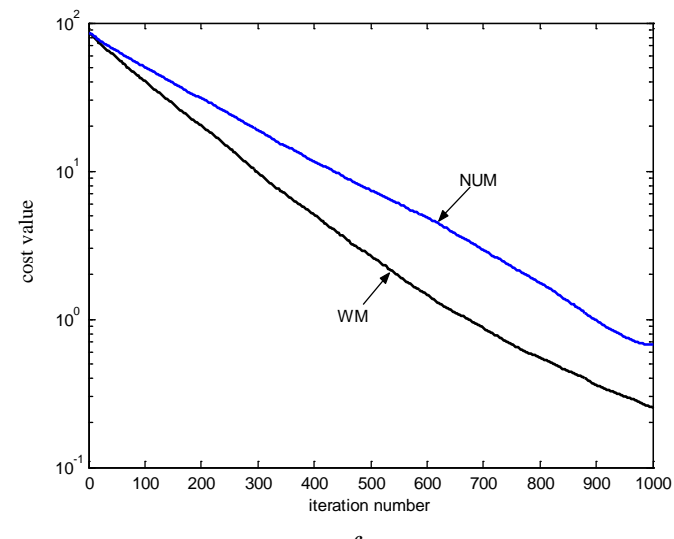

$f_{5}$

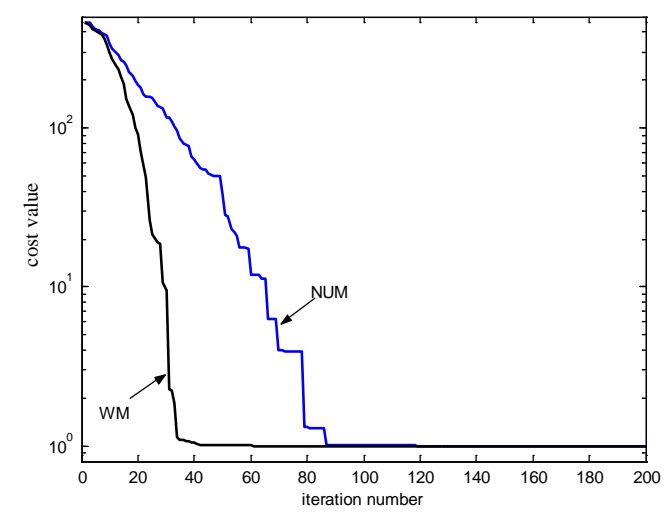

$f_{8}$

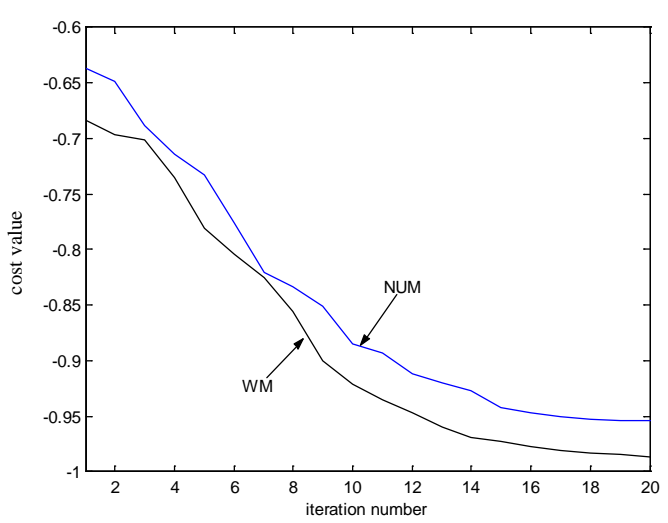

$f_{10}$

Fig. 9. Comparison between WM and NUM for $f_{1}$ to $f_{10}$ (except $f_{3}$ and $f_{7}$ ) without the crossover operation. All results are averaged ones over 50 runs. 


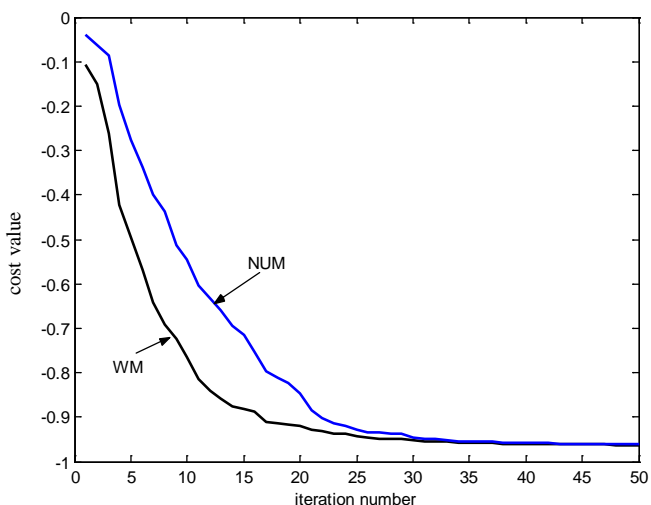

$f_{11}$

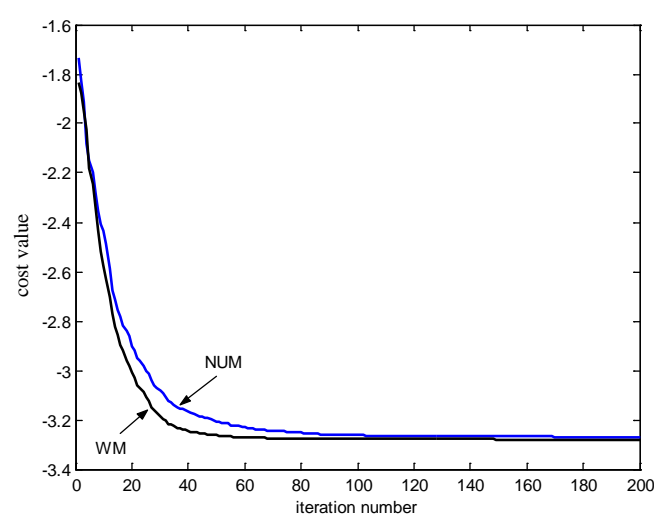

$f_{13}$

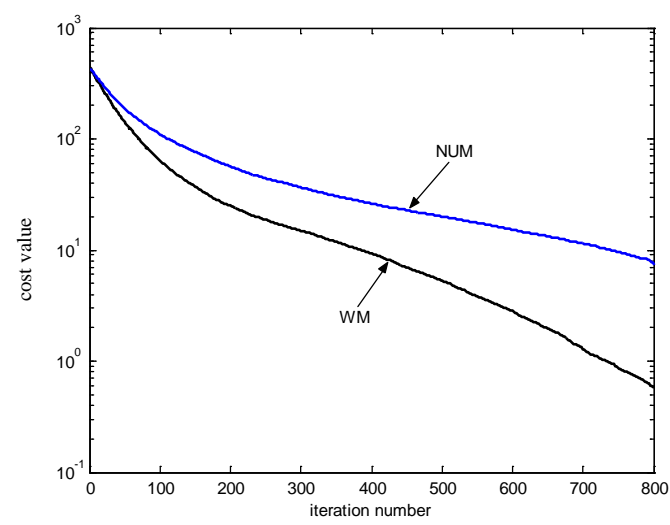

$f_{15}$

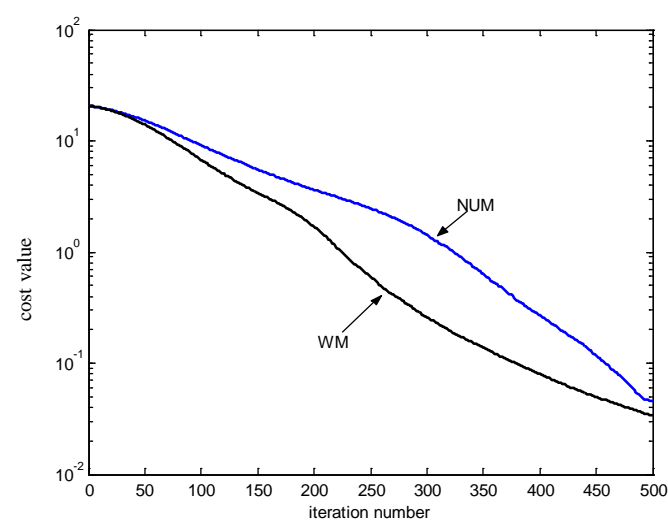

$f_{17}$

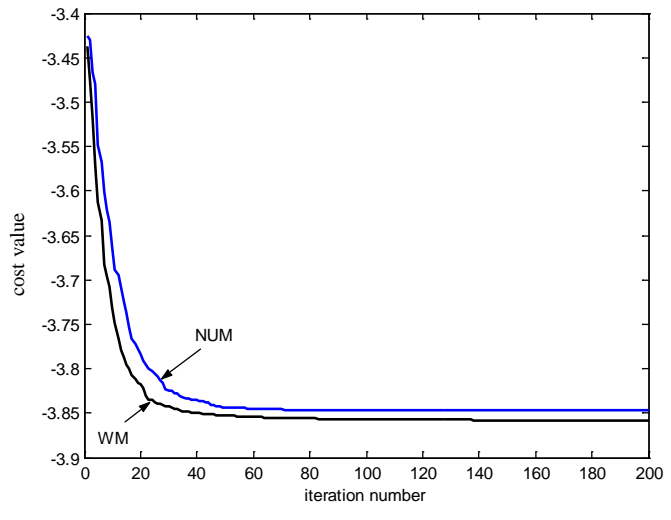

$f_{12}$

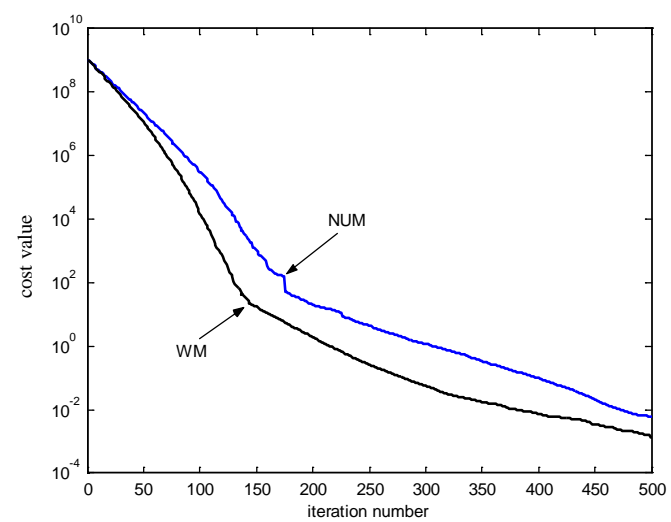

$f_{14}$

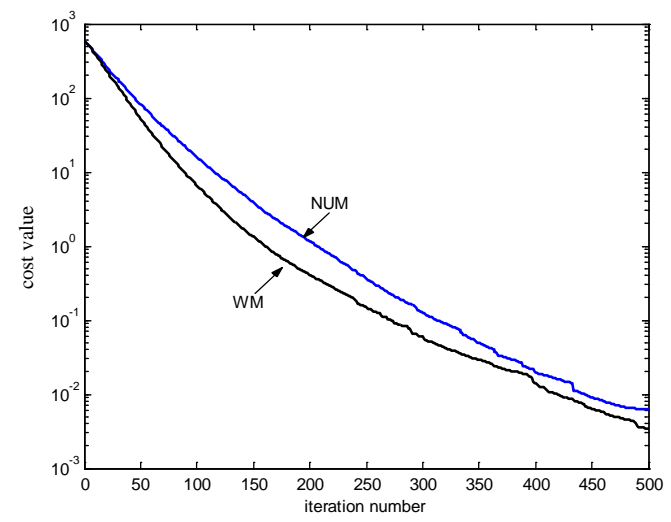

$f_{16}$

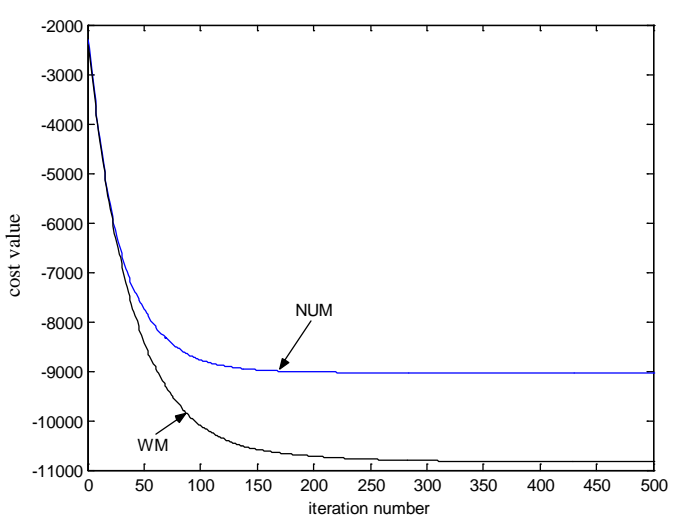

$f_{18}$

Fig. 10. Comparison between WM and NUM for $f_{11}$ to $f_{18}$ without the crossover operation. All results are averaged ones over 50 runs. 


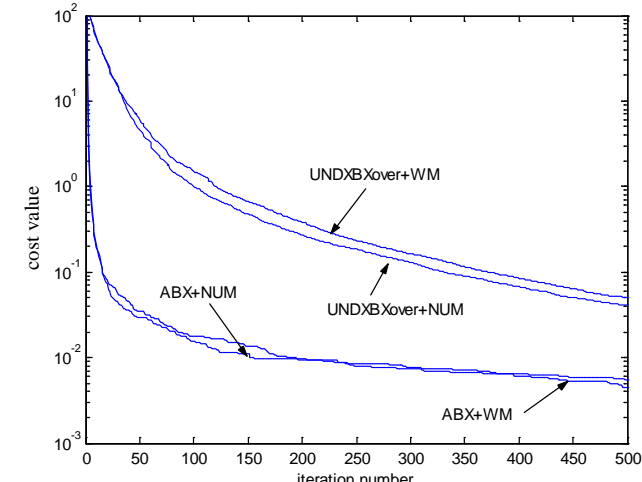

(a)

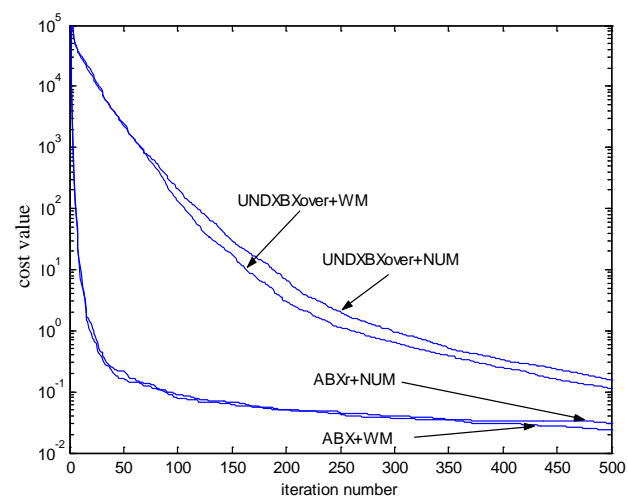

(c)

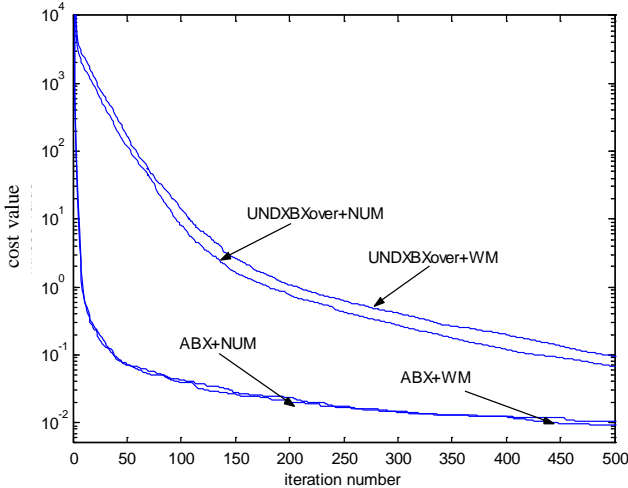

(b)

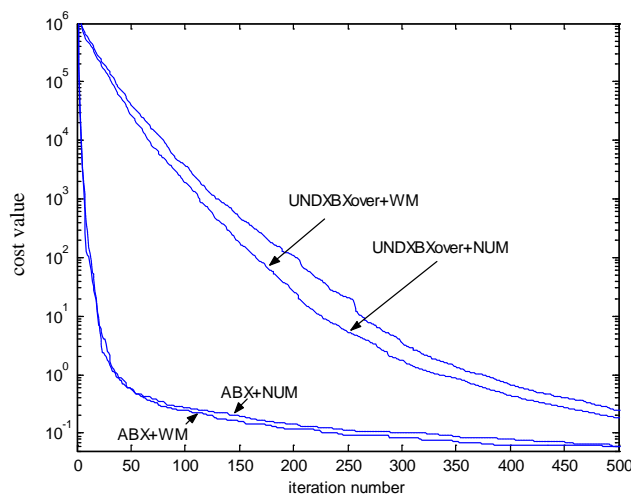

(d)

Fig. 11. Comparison between different genetic operations for $f_{4}$ with different initial ranges of variables. All results are averaged over 50 runs.

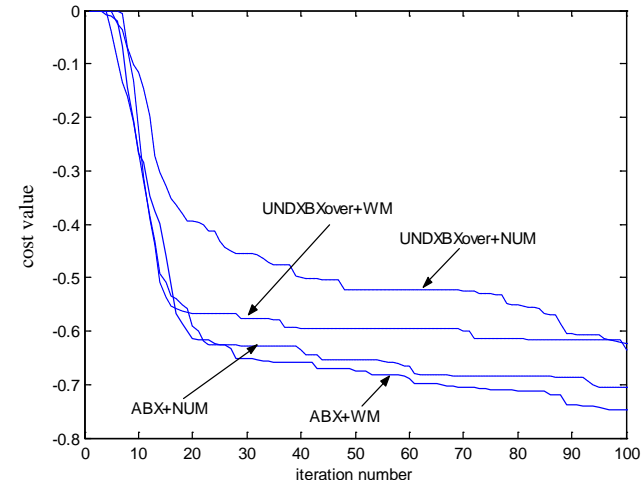

(a)

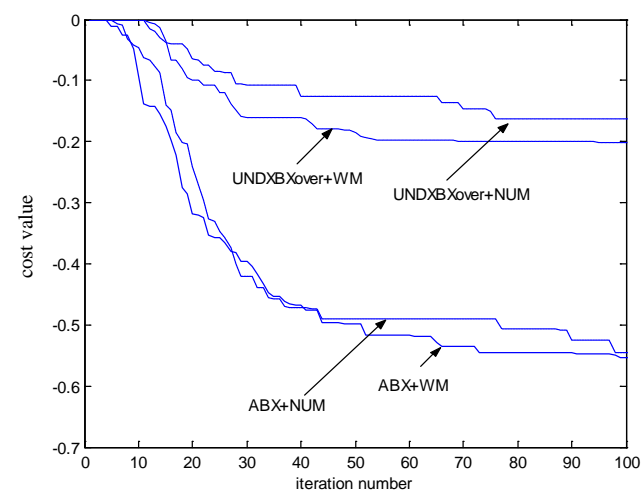

(c)

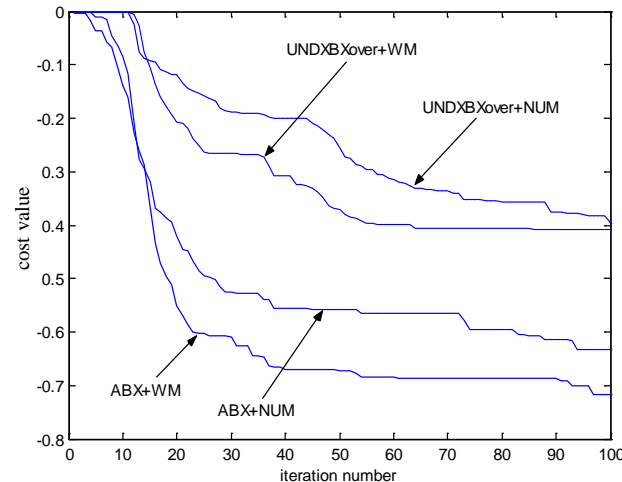

(b)

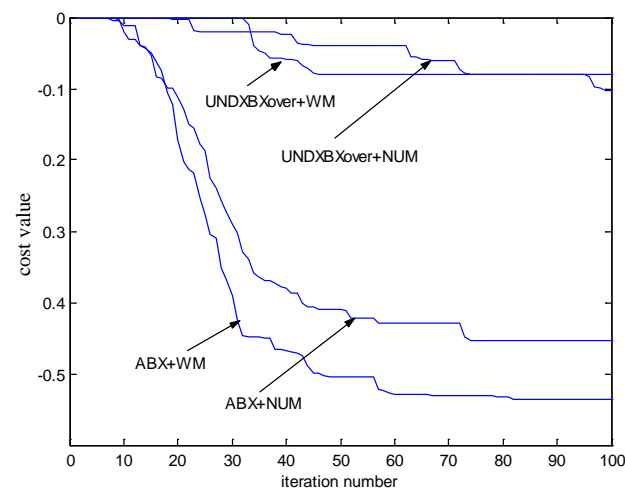

(d)

Fig. 12. Comparison between different genetic operations for $f_{7}$ with different initial ranges of variables. All results are averaged ones over 50 runs. 


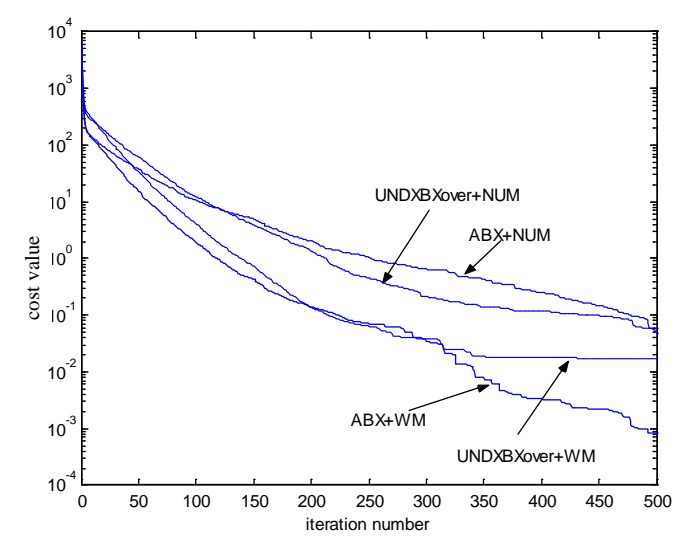

(a)

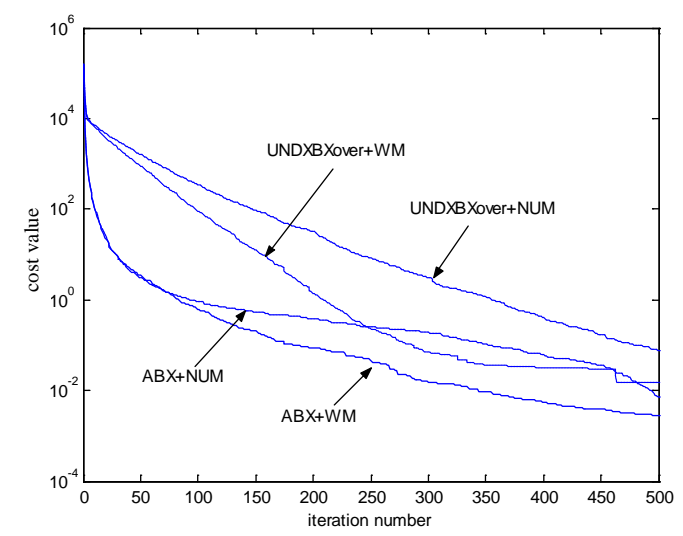

(c)

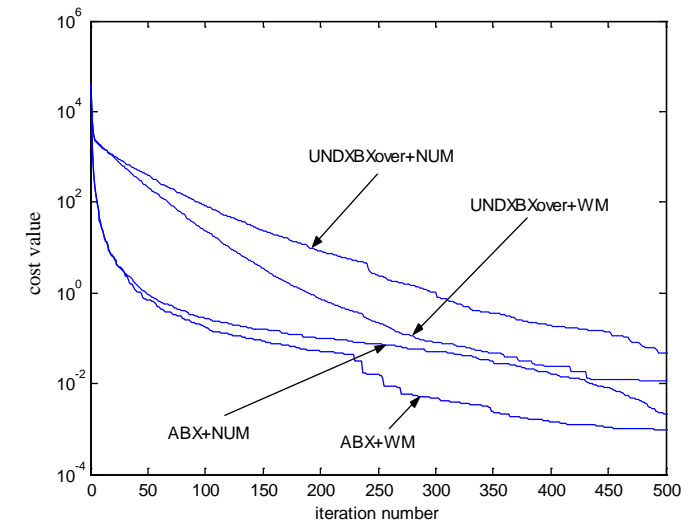

(b)

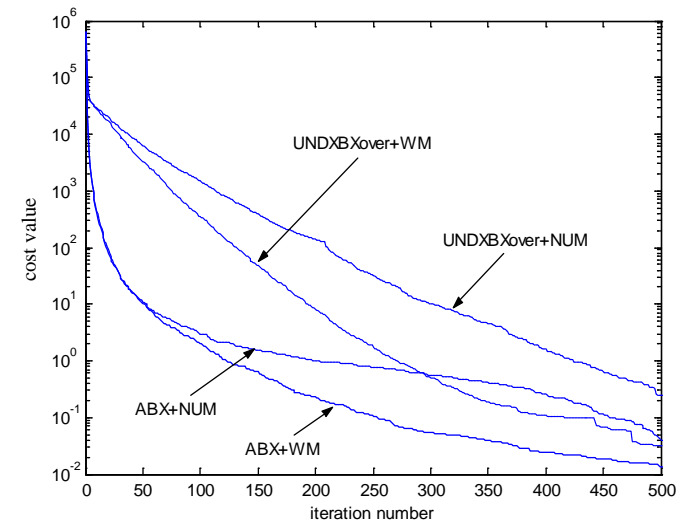

(d)

Fig. 13. Comparison between different genetic operations for $f_{16}$ with different initial ranges of vriables. All results are averaged ones over 50 runs.

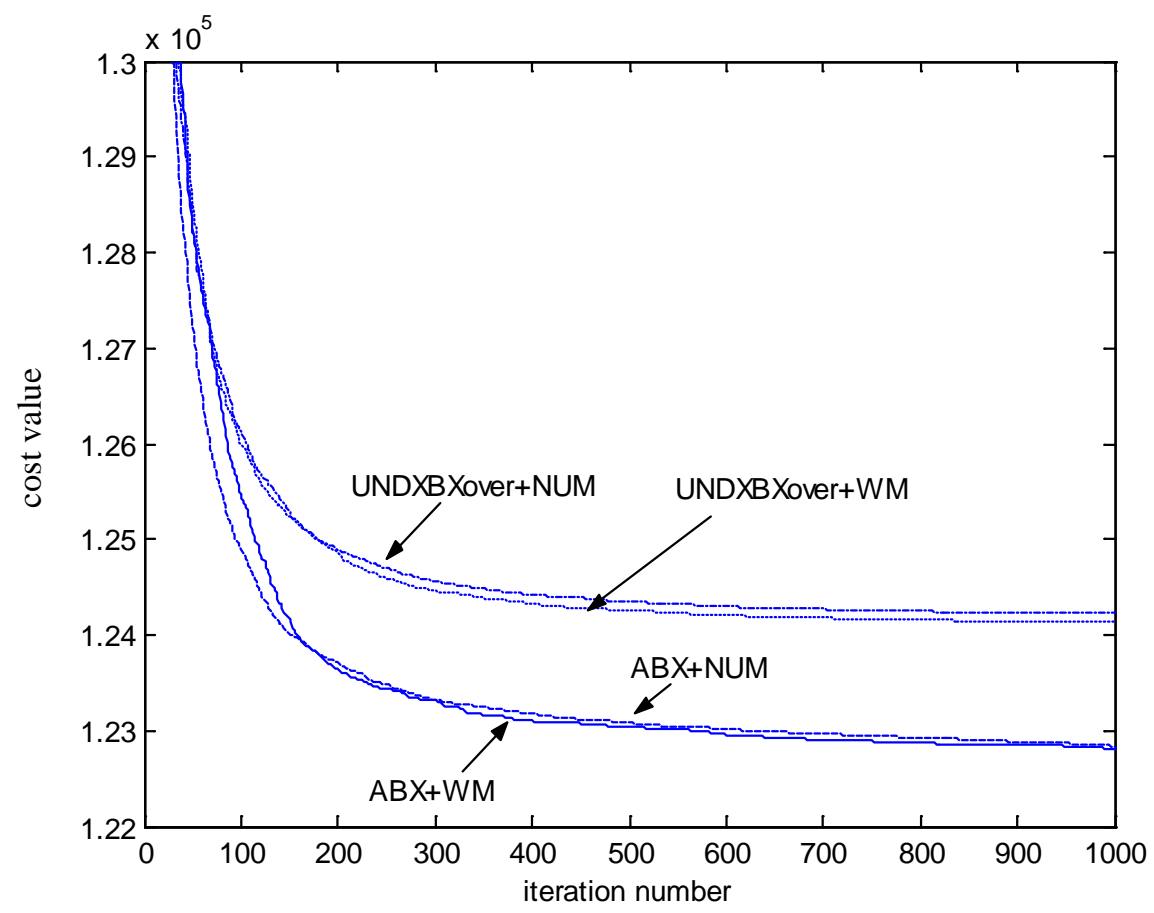

Fig. 14. Comparisons between different genetic operations for ELD. All results are averaged ones over 50 runs. 


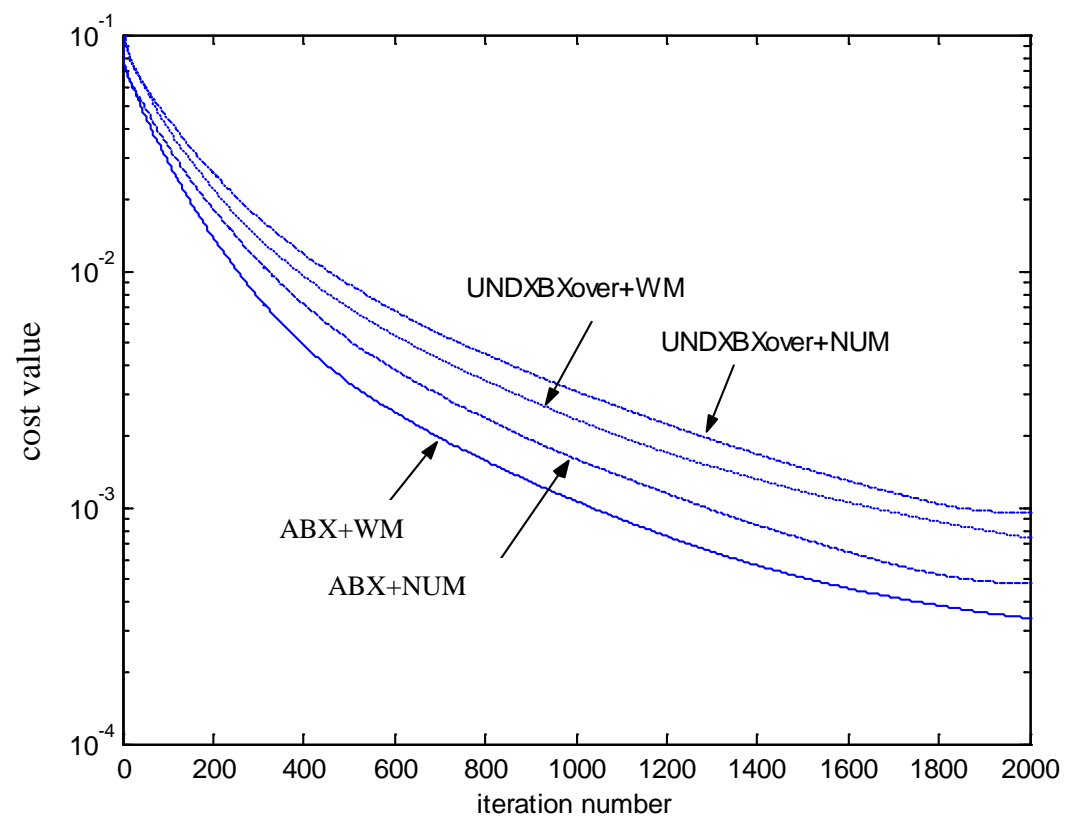

Fig. 15. Comparisons between different genetic operations for tuning associative memory. All results are averaged ones over 50 runs. 


\begin{tabular}{|c|c|c|c|c|}
\hline \multicolumn{5}{|c|}{$f_{1}\left(\times 10^{-4}\right)$, number of iteration: 500} \\
\hline & $\mathrm{ABX}+\mathrm{WM}$ & $\mathrm{ABX}+\mathrm{NUM}$ & UNDXBXover+WM & UNDXBXover+NUM \\
\hline Mean & 1.6139 & 4.1263 & 4.0840 & 12.614 \\
\hline Best & 0.00048 & 0.0205 & 0.6095 & 4.5084 \\
\hline Std Dev & 2.9147 & 5.1841 & 4.0513 & 6.7184 \\
\hline \multicolumn{5}{|c|}{$t$-test $([\mathrm{ABX}+\mathrm{WM}]-[$ UNDXBXover+NUM] $)=-10.62$} \\
\hline \multicolumn{5}{|c|}{$f_{2}\left(\times 10^{-2}\right)$, number of iteration: 500} \\
\hline & $\mathrm{ABX}+\mathrm{WM}$ & $\mathrm{ABX}+\mathrm{NUM}$ & UNDXBXover+WM & UNDXBXover+NUM \\
\hline Mean & 0.24781 & 0.38064 & 2768.9 & 2785.1 \\
\hline Best & 0.02396 & 0.01624 & 2660.0 & 2638.0 \\
\hline Std Dev & 0.16678 & 0.35854 & 59.999 & 62.845 \\
\hline \multicolumn{5}{|c|}{$t$-test $([\mathrm{ABX}+\mathrm{WM}]-[\mathrm{UNDXBXover}+\mathrm{NUM}])=-313.3$} \\
\hline
\end{tabular}

\begin{tabular}{ccccc}
\hline \multicolumn{4}{c}{$f_{3}\left(\times 10^{0}\right)$, number of iteration: 200} \\
\hline Mean & ABX+WM & ABX+NUM & UNDXBXover+WM & UNDXBXover+NUM \\
Best & $\mathbf{0}$ & $\mathbf{0}$ & 10.180 & 12.640 \\
Std Dev & $\mathbf{0}$ & $\mathbf{0}$ & 1.0000 & 3.0000 \\
$t$-test $([\mathrm{ABX}+\mathrm{WM}]-[$ UNDXBXover+NUM]) $=-15.81$ & 5.0130 & 5.6524 \\
\hline
\end{tabular}

\begin{tabular}{ccccc}
\hline \multicolumn{5}{c}{$f_{4}\left(\times 10^{-3}\right)$, number of iteration: 500} \\
\hline Mean & $\mathrm{ABX}+\mathrm{WM}$ & $\mathrm{ABX}+\mathrm{NUM}$ & UNDXBXover+WM & UNDXBXover+NUM \\
Best & $\mathbf{1 . 5 5 0 3}$ & 2.7952 & 67.758 & 87.028 \\
Std Dev & $\mathbf{0 . 2 1 3 2}$ & 0.4589 & 15.052 & 20.588 \\
& $\mathbf{1 . 0 5 3 3}$ & 2.1315 & 76.725 & 62.560
\end{tabular}

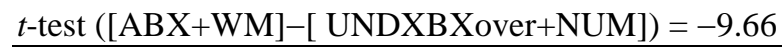

\begin{tabular}{ccccc}
\hline \multicolumn{5}{c}{} \\
\hline \multicolumn{5}{c}{$f_{5}\left(\times 10^{-2}\right)$, number of iteration: 500} \\
\hline Mean & ABX+WM & ABX+NUM & UNDXBXover+WM & UNDXBXover+NUM \\
Best & $\mathbf{0 . 5 5 9 6}$ & 0.6207 & 654.10 & 747.30 \\
Std Dev & $\mathbf{0 . 0 0 7 2}$ & 0.0503 & 201.66 & 214.20 \\
$t$-test ([ABX+WM]-[ UNDXBXover+NUM]) $=-10.35$ & 378.04 & 510.33 \\
\hline
\end{tabular}

\begin{tabular}{ccccc}
\hline \multicolumn{5}{c}{$f_{6}\left(\times 10^{-2}\right)$, number of iteration: 500} \\
\hline Mean & ABX+WM & ABX+NUM & UNDXBXover+WM & UNDXBXover+NUM \\
Best & $\mathbf{1 . 4 9 2 4}$ & 1.6115 & 7.9237 & 14.158 \\
Std Dev & 0.1194 & $\mathbf{0 . 0 7 6 9}$ & 0.5154 & 0.8621 \\
$t$-test $([\mathrm{ABX}+\mathrm{WM}]-[$ UNDXBXover+NUM]) $=-7.86$ & 6.5454 & 11.366 \\
\hline
\end{tabular}

\begin{tabular}{|c|c|c|c|c|}
\hline \multicolumn{5}{|c|}{$f_{7}\left(\times 10^{0}\right)$, number of iteration: 100} \\
\hline & $\mathrm{ABX}+\mathrm{WM}$ & $\mathrm{ABX}+\mathrm{NUM}$ & UNDXBXover+WM & UNDXBXover+NUM \\
\hline Mean & -0.9721 & -0.9549 & -0.8679 & -0.8365 \\
\hline Best & -1.0000 & -0.9999 & -1.0000 & -1.0000 \\
\hline Std Dev & 0.0530 & 0.1198 & 0.3277 & 0.3689 \\
\hline \multicolumn{5}{|c|}{$t$-test $([\mathrm{ABX}+\mathrm{WM}]-[\mathrm{UNDXBXover}+\mathrm{NUM}])=-2.57$} \\
\hline
\end{tabular}

Table I. Comparison between different genetic operations for $f_{1}$ to $f_{7}$. All results are averaged ones over 50 runs. 


\begin{tabular}{|c|c|c|c|c|}
\hline \multicolumn{5}{|c|}{$f_{8}\left(\times 10^{0}\right)$, number of iteration: 50} \\
\hline & $\mathrm{ABX}+\mathrm{WM}$ & $\mathrm{ABX}+\mathrm{NUM}$ & UNDXBXover+WM & UNDXBXover+NUM \\
\hline Mean & 0.9980 & 0.9980 & 0.9980 & 0.9980 \\
\hline Best & 0.9980 & 0.9980 & 0.9980 & 0.9980 \\
\hline Std Dev & $1.0277 \times 10^{-7}$ & $1.3308 \times 10^{-5}$ & $1.3370 \times 10^{-7}$ & $2.5832 \times 10^{-5}$ \\
\hline \multicolumn{5}{|c|}{$t$-test $([\mathrm{ABX}+\mathrm{WM}]-[$ UNDXBXover+NUM] $)=\mathrm{N} / \mathrm{A}$} \\
\hline
\end{tabular}

\begin{tabular}{ccccc}
\hline \multicolumn{4}{c}{$f_{9}\left(\times 10^{-4}\right)$, number of iteration: 200} \\
\hline Mean & $\mathbf{A B X}+\mathrm{WM}$ & $\mathrm{ABX}+\mathrm{NUM}$ & UNDXBXover+WM & UNDXBXover+NUM \\
Best & $\mathbf{3 . 1 0 0 2}$ & 6.3380 & 17.863 & 29.451 \\
Std Dev & 2.7085 & 3.3428 & 3.3147 & 5.1236 \\
$t$-test $([\mathrm{ABX}+\mathrm{WM}]-[$ UNDXBXover+NUM]) $=-26.94$ & 36.986 & 5.5539 \\
\hline
\end{tabular}

\begin{tabular}{ccccc}
\hline \multicolumn{5}{c}{$f_{10}\left(\times 10^{0}\right)$, number of iteration: 20} \\
\hline ABX+WM & ABX+NUM & UNDXBXover+WM & UNDXBXover+NUM \\
\hline Mean & $-\mathbf{1}$ & $-\mathbf{1}$ & $-\mathbf{1}$ & $-\mathbf{1}$ \\
Best & $-\mathbf{1}$ & $-\mathbf{1}$ & $-\mathbf{1}$ & $-\mathbf{1}$ \\
Std Dev & $\mathbf{0}$ & $\mathbf{0}$ & $3.2770 \times 10^{-4}$ & $5.3212 \times 10^{-4}$ \\
$t$-test $([\mathrm{ABX}+\mathrm{WM}]-[\mathrm{UNDXBXover+NUM])}=\mathrm{N} / \mathrm{A}$ & & \\
\hline
\end{tabular}

\begin{tabular}{ccccc}
\hline \multicolumn{5}{c}{$f_{11}\left(\times 10^{0}\right)$, number of iteration: 50 } \\
\hline ABX+WM & ABX+NUM & UNDXBXover+WM & UNDXBXover+NUM \\
\hline Bean & $\mathbf{- 1 . 0 3 1 6}$ & -1.0315 & $-\mathbf{1 . 0 3 1 6}$ & -1.0153 \\
Std Dev & $\mathbf{- 1 . 0 3 1 6}$ & $-\mathbf{1 . 0 3 1 6}$ & $-\mathbf{1 . 0 3 1 6}$ & $-\mathbf{1 . 0 3 1 6}$ \\
$t$-test $([\mathrm{ABX}+\mathrm{WM}]-[$ UNDXBXover+NUM]) $=-1.00$ & $1.5767 \times 10^{-5}$ & $7.7364 \times 10^{-4}$ & $1.1542 \times 10^{-1}$ \\
\hline
\end{tabular}

\begin{tabular}{|c|c|c|c|c|}
\hline \multicolumn{5}{|c|}{$f_{12}\left(\times 10^{0}\right)$, number of iteration: 100} \\
\hline & $\mathrm{ABX}+\mathrm{WM}$ & $\mathrm{ABX}+\mathrm{NUM}$ & UNDXBXover+WM & UNDXBXover+NUM \\
\hline Mean & -3.8628 & -3.8627 & -3.8591 & -3.8628 \\
\hline Best & -3.8628 & -3.8628 & -3.8628 & -3.8628 \\
\hline Std Dev & $2.9850 \times 10^{-4}$ & $2.0403 \times 10^{-3}$ & $1.0288 \times 10^{-1}$ & $1.0858 \times 10^{-3}$ \\
\hline \multicolumn{5}{|c|}{ t-test $([\mathrm{ABX}+\mathrm{WM}]-[$ UNDXBXover+NUM] $)=\mathrm{N} / \mathrm{A}$} \\
\hline
\end{tabular}

\begin{tabular}{|c|c|c|c|c|}
\hline \multicolumn{5}{|c|}{$f_{13}\left(\times 10^{0}\right)$, number of iteration: 100} \\
\hline & $\mathrm{ABX}+\mathrm{WM}$ & $\mathrm{ABX}+\mathrm{NUM}$ & UNDXBXover+WM & UNDXBXover+NUM \\
\hline Mean & -3.3051 & -3.3061 & -3.2837 & -3.2905 \\
\hline Best & -3.3220 & -3.3220 & -3.3220 & -3.3220 \\
\hline Std Dev & $4.1617 \times 10^{-2}$ & $4.0406 \times 10^{-2}$ & $5.6158 \times 10^{-2}$ & $5.3560 \times 10^{-2}$ \\
\hline \multicolumn{5}{|c|}{$t$-test $([\mathrm{ABX}+\mathrm{WM}]-[$ UNDXBXover+NUM] $)=-1.55$} \\
\hline
\end{tabular}

Table II. Comparison between different genetic operations on $f_{8}$ to $f_{13}$. All results are averaged ones over 50 runs. 


\begin{tabular}{|c|c|c|c|c|}
\hline \multicolumn{5}{|c|}{$f_{14}\left(\times 10^{-4}\right)$, number of iteration: 500} \\
\hline & $\mathrm{ABX}+\mathrm{WM}$ & $\mathrm{ABX}+\mathrm{NUM}$ & UNDXBXover+WM & UNDXBXover+NUM \\
\hline Mean & 0.6791 & 14.340 & 10.181 & 38.643 \\
\hline Best & 0.0155 & 0.0413 & 0.7273 & 0.3654 \\
\hline Std Dev & 1.1437 & 36.254 & 22.759 & 51.452 \\
\hline \multicolumn{5}{|c|}{$t$-test $([\mathrm{ABX}+\mathrm{WM}]-[$ UNDXBXover+NUM] $)=-5.22$} \\
\hline \multicolumn{5}{|c|}{$f_{15}\left(\times 10^{-3}\right)$, number of iteration: 800} \\
\hline & $\mathrm{ABX}+\mathrm{WM}$ & $\mathrm{ABX}+\mathrm{NUM}$ & UNDXBXover+WM & UNDXBXover+NUM \\
\hline Mean & 2.8729 & 5.6010 & 283.16 & 616.92 \\
\hline Best & 0.1817 & 0.2907 & 0.8134 & 0.6561 \\
\hline Std Dev & 2.4540 & 5.5464 & 534.34 & 940.46 \\
\hline \multicolumn{5}{|c|}{$t$-test $([\mathrm{ABX}+\mathrm{WM}]-[\mathrm{UNDXBXover}+\mathrm{NUM}])=-4.62$} \\
\hline \multicolumn{5}{|c|}{$f_{16}\left(\times 10^{-5}\right)$, number of iteration: 500} \\
\hline & $\mathrm{ABX}+\mathrm{WM}$ & $\mathrm{ABX}+\mathrm{NUM}$ & UNDXBXover+WM & UNDXBXover+NUM \\
\hline Mean & 6.3267 & 109.63 & 1174.3 & 1797.4 \\
\hline Best & 0.1832 & 5.0020 & 1.7688 & 6.0472 \\
\hline Std Dev & 6.1773 & 81.434 & 5773.2 & 6998.2 \\
\hline \multicolumn{5}{|c|}{$t$-test $([\mathrm{ABX}+\mathrm{WM}]-[$ UNDXBXover+NUM] $)=-1.81$} \\
\hline \multicolumn{5}{|c|}{$f_{17}\left(\times 10^{-3}\right)$, number of iteration: 500} \\
\hline & $\mathrm{ABX}+\mathrm{WM}$ & $\mathrm{ABX}+\mathrm{NUM}$ & UNDXBXover+WM & UNDXBXover+NUM \\
\hline Mean & 1.3444 & 1.7323 & 10.543 & 14.665 \\
\hline Best & 0.0203 & 0.0655 & 5.2554 & 4.1783 \\
\hline Std Dev & 1.7323 & 1.9284 & 4.0336 & 6.6873 \\
\hline \multicolumn{5}{|c|}{$t$-test $([\mathrm{ABX}+\mathrm{WM}]-[$ UNDXBXover+NUM] $)=-13.63$} \\
\hline \multicolumn{5}{|c|}{$f_{18}\left(\times 10^{0}\right)$, number of iteration: 500} \\
\hline & $\mathrm{ABX}+\mathrm{WM}$ & $\mathrm{ABX}+\mathrm{NUM}$ & UNDXBXover+WM & UNDXBXover+NUM \\
\hline Mean & -12569.3 & -12596.2 & -10261.9 & -10188.9 \\
\hline Best & -12569.5 & -12569.5 & -11168.0 & -11089.0 \\
\hline Std Dev & 0.1520 & 0.2914 & 431.80 & 473.84 \\
\hline$t$-test $([\mathrm{ABX}$ & $-[$ UNDXBX & $M])=-35.52$ & & \\
\hline
\end{tabular}

Table III. Comparison between different genetic operations for $f_{14}$ to $f_{18}$. All results are averaged ones over 50 runs. 


\begin{tabular}{|c|c|c|c|c|c|c|c|c|}
\hline \multirow[b]{2}{*}{ Function } & \multirow[b]{2}{*}{$\begin{array}{c}\text { Number } \\
\text { of } \\
\text { iteration }\end{array}$} & \multicolumn{3}{|c|}{ Wavelet Mutation (WM) } & \multicolumn{3}{|c|}{ Non-Uniform Mutation (NUM) } & \multirow[b]{2}{*}{$\begin{array}{c}t \text {-test } \\
(\mathrm{WM}-\mathrm{NUM})\end{array}$} \\
\hline & & Mean & Best & Std Dev & Mean & Best & Std Dev & \\
\hline$f_{1}\left(\times 10^{-3}\right)$ & 500 & 4.0356 & 1.0634 & 0.9161 & 40.071 & 12.832 & 19.287 & -13.197 \\
\hline$f_{2}\left(\times 10^{1}\right)$ & 500 & 3.8008 & 0.4671 & 2.3051 & 5.9549 & 0.9366 & 3.2204 & -3.8461 \\
\hline$f_{4}\left(\times 10^{-2}\right)$ & 500 & 5.2538 & 1.9215 & 1.8577 & 8.8118 & 2.9487 & 2.9853 & -7.1553 \\
\hline$f_{5}\left(\times 10^{-1}\right)$ & 1000 & 2.5280 & 1.5811 & 0.5138 & 6.7490 & 3.4751 & 2.0596 & -14.061 \\
\hline$f_{6}\left(\times 10^{-2}\right)$ & 500 & 2.2759 & 1.0900 & 0.6494 & 2.4184 & 1.4767 & 0.6972 & -1.0576 \\
\hline$f_{8}\left(\times 10^{0}\right)$ & 200 & 0.9980 & 0.9980 & $7.3982 \times 10^{-11}$ & 0.9980 & 0.9980 & $2.9079 \times 10^{-10}$ & N/A \\
\hline$f_{9}\left(\times 10^{-3}\right)$ & 200 & 9.3282 & 0.6078 & 9.6548 & 13.393 & 0.5910 & 17.639 & -1.4294 \\
\hline$f_{10}\left(\times 10^{0}\right)$ & 20 & -0.9861 & -1.0000 & 0.0212 & -0.9537 & -1.0000 & 0.1283 & -1.7618 \\
\hline$f_{11}\left(\times 10^{0}\right)$ & 50 & -0.9627 & -1.0316 & 0.2614 & -0.9599 & -1.0316 & 0.2239 & -0.0575 \\
\hline$f_{12}\left(\times 10^{0}\right)$ & 200 & -3.8583 & -3.8628 & 0.0078 & -3.8473 & -3.8628 & 0.1093 & -0.7098 \\
\hline$f_{13}\left(\times 10^{0}\right)$ & 200 & -3.2791 & -3.3220 & 0.0577 & -3.2695 & -3.3220 & 0.0597 & -0.8176 \\
\hline$f_{14}\left(\times 10^{-3}\right)$ & 500 & 1.2887 & 0.3558 & 0.8485 & 6.3054 & 0.5732 & 5.5154 & -6.3569 \\
\hline$f_{15}\left(\times 10^{0}\right)$ & 800 & 0.5777 & 0.1783 & 0.3784 & 7.4349 & 4.6367 & 1.4969 & -31.404 \\
\hline$f_{16}\left(\times 10^{-3}\right)$ & 500 & 3.3964 & 0.6255 & 2.7778 & 6.3268 & 0.1243 & 41.201 & -0.5018 \\
\hline$f_{17}\left(\times 10^{-2}\right)$ & 500 & 3.3688 & 2.1860 & 0.4944 & 4.6260 & 2.3877 & 1.0430 & -7.7018 \\
\hline$f_{18}\left(\times 10^{0}\right)$ & 500 & -10837.4 & -11502.9 & 315.1 & -9035.1 & -10101.9 & 472.7 & -8.7163 \\
\hline
\end{tabular}

Table IV. Comparison between WM and NUM for $f_{1}$ to $f_{18}$ (except $f_{3}$ and $f_{7}$ ) without crossover operations. All results are averaged ones over 50 runs.

\begin{tabular}{ccccccc}
\hline Function & $\begin{array}{c}\text { Number } \\
\text { of } \\
\text { iteration }\end{array}$ & $\zeta=0.2$ & $\zeta=0.5$ & $\zeta=1.0$ & $\zeta=2.0$ & $\zeta=5.0$ \\
\hline$f_{1}\left(\times 10^{-4}\right)$ & 500 & 92.259 & 32.283 & 10.997 & 7.9005 & $\mathbf{1 . 6 1 3 9}$ \\
$f_{2}\left(\times 10^{-2}\right)$ & 500 & 4.3312 & 2.1228 & 1.4416 & 0.9221 & $\mathbf{0 . 2 4 7 8}$ \\
$f_{3}\left(\times 10^{0}\right)$ & 200 & 0 & $\mathbf{0}$ & 0 & 0 & 0 \\
$f_{4}\left(\times 10^{-3}\right)$ & 500 & 2.2760 & 2.0321 & 1.9075 & $\mathbf{1 . 5 5 0 3}$ & 1.7121 \\
$f_{5}\left(\times 10^{-2}\right)$ & 500 & 1.5283 & 1.4216 & 1.0127 & $\mathbf{0 . 5 5 9 6}$ & 0.6012 \\
$f_{6}\left(\times 10^{-2}\right)$ & 500 & 14.552 & 10.062 & 5.2128 & 2.1627 & $\mathbf{1 . 4 9 2 4}$ \\
$f_{7}\left(\times 10^{0}\right)$ & 100 & -0.7511 & $-\mathbf{0 . 9 7 2 1}$ & -0.9592 & -0.9296 & -0.8918 \\
$f_{8}\left(\times 10^{0}\right)$ & 50 & 1.0065 & 0.9983 & 0.9980 & $\mathbf{0 . 9 9 8 0}$ & 1.8193 \\
$f_{9}\left(\times 10^{-4}\right)$ & 200 & 7.4659 & 6.1928 & 6.3950 & $\mathbf{5 . 9 1 2 5}$ & 6.4783 \\
$f_{10}\left(\times 10^{0}\right)$ & 20 & -1.0000 & -1.0000 & -1.0000 & $-\mathbf{1 . 0 0 0 0}$ & -1.0000 \\
$f_{11}\left(\times 10^{0}\right)$ & 50 & -1.0300 & -1.0314 & -1.0316 & -1.0316 & $-\mathbf{1 . 0 3 1 6}$ \\
$f_{12}\left(\times 10^{0}\right)$ & 100 & -3.8627 & -3.8627 & -3.8302 & -3.8509 & -3.8471 \\
$f_{13}\left(\times 10^{0}\right)$ & 100 & -3.3051 & -3.3026 & -3.2868 & -3.2639 & -3.1642 \\
$f_{14}\left(\times 10^{-4}\right)$ & 500 & $\mathbf{0 . 6 7 9 1}$ & 1.0792 & 3.2004 & 2.4721 & 7.8236 \\
$f_{15}\left(\times 10^{-3}\right)$ & 800 & 42.220 & 10.684 & 5.2720 & 3.3008 & $\mathbf{2 . 8 7 2 9}$ \\
$f_{16}\left(\times 10^{-5}\right)$ & 500 & 115.42 & 59.412 & 18.244 & 8.0794 & $\mathbf{6 . 3 2 6 7}$ \\
$f_{17}\left(\times 10^{-3}\right)$ & 500 & 12.798 & 3.8139 & 3.5067 & 2.1405 & $\mathbf{1 . 3 4 4 4}$ \\
$f_{18}\left(\times 10^{-5}\right)$ & 500 & -12564.4 & -12568.8 & -12569.1 & $\mathbf{- 1 2 5 6 9 . 4}$ & -12569.4 \\
\hline
\end{tabular}

Table V. The mean cost values offered by wavelet mutation with different shape parameter $\zeta$ for function $f_{1}$ to $f_{18}$. 


\begin{tabular}{|c|c|c|c|c|}
\hline \multicolumn{5}{|c|}{$f_{4}\left(\times 10^{-3}\right)$, number of iteration: 500} \\
\hline \multicolumn{5}{|c|}{ Initial range: $-2.56 \leq x_{i} \leq 5.12$} \\
\hline & $\mathrm{ABX}+\mathrm{WM}$ & $\mathrm{ABX}+\mathrm{NUM}$ & UNDXBXover+WM & UNDXBXover+NUM \\
\hline Mean & 4.4350 & 5.4386 & 41.007 & 50.831 \\
\hline Best & 0.2907 & 0.5751 & 17.663 & 23.658 \\
\hline Std Dev & 3.2943 & 4.0096 & 14.109 & 14.128 \\
\hline \multicolumn{5}{|c|}{ Initial range: $-6.4 \leq x_{i} \leq 12.8$} \\
\hline & $\mathrm{ABX}+\mathrm{WM}$ & $\mathrm{ABX}+\mathrm{NUM}$ & UNDXBXover+WM & UNDXBXover+NUM \\
\hline Mean & 9.1618 & 10.376 & 68.112 & 96.057 \\
\hline Best & 0.4297 & 0.3694 & 16.741 & 31.761 \\
\hline Std Dev & 5.6406 & 8.2521 & 23.898 & 40.070 \\
\hline \multicolumn{5}{|c|}{ Initial range: $-12.8 \leq x_{i} \leq 25.6$} \\
\hline & $\mathrm{ABX}+\mathrm{WM}$ & $\mathrm{ABX}+\mathrm{NUM}$ & UNDXBXover+WM & UNDXBXover+NUM \\
\hline Mean & 23.982 & 30.784 & 113.54 & 154.85 \\
\hline Best & 3.0393 & 0.8271 & 47.182 & 62.557 \\
\hline Std Dev & 14.305 & 26.989 & 36.270 & 62.135 \\
\hline \multicolumn{5}{|c|}{ Initial range: $-25.6 \leq x_{i} \leq 51.2$} \\
\hline & $\mathrm{ABX}+\mathrm{WM}$ & $\mathrm{ABX}+\mathrm{NUM}$ & UNDXBXover+WM & UNDXBXover+NUM \\
\hline Mean & 59.699 & 60.358 & 182.00 & 241.12 \\
\hline Best & 6.0383 & 5.3199 & 56.256 & 94.396 \\
\hline Std Dev & 35.603 & 37.199 & 72.225 & 81.600 \\
\hline
\end{tabular}

Table VI. Comparison between different operations for $f_{4}$ with different initial ranges of variables. All results are averaged ones over 50 runs. 


\begin{tabular}{|c|c|c|c|c|}
\hline \multicolumn{5}{|c|}{$f_{7}\left(\times 10^{0}\right)$, number of iteration: 100} \\
\hline \multicolumn{5}{|c|}{ Initial range: $-600 \leq x_{i} \leq 600$} \\
\hline & $\mathrm{ABX}+\mathrm{WM}$ & $\mathrm{ABX}+\mathrm{NUM}$ & UNDXBXover+WM & UNDXBXover+NUM \\
\hline Mean & 0.7471 & 0.7062 & 0.6355 & 0.6227 \\
\hline Best & 1.0000 & 1.0000 & 1.0000 & 1.0000 \\
\hline Std Dev & 0.3417 & 0.3476 & 0.4820 & 0.4768 \\
\hline \multicolumn{5}{|c|}{ Initial range: $-1500 \leq x_{i} \leq 1500$} \\
\hline & $\mathrm{ABX}+\mathrm{WM}$ & $\mathrm{ABX}+\mathrm{NUM}$ & UNDXBXover+WM & UNDXBXover+NUM \\
\hline Mean & 0.7168 & 0.6338 & 0.4079 & 0.3968 \\
\hline Best & 1.0000 & 1.0000 & 1.0000 & 1.0000 \\
\hline Std Dev & 0.3669 & 0.3863 & 0.4899 & 0.4656 \\
\hline \multicolumn{5}{|c|}{ Initial range: $-3000 \leq x_{i} \leq 3000$} \\
\hline & $\mathrm{ABX}+\mathrm{WM}$ & $\mathrm{ABX}+\mathrm{NUM}$ & UNDXBXover+WM & UNDXBXover+NUM \\
\hline Mean & 0.5527 & 0.5451 & 0.2019 & 0.1626 \\
\hline Best & 1.0000 & 1.0000 & 1.0000 & 1.0000 \\
\hline Std Dev & 0.4206 & 0.4114 & 0.4030 & 0.3544 \\
\hline \multicolumn{5}{|c|}{ Initial range: $-60000 \leq x_{i} \leq 60000$} \\
\hline & $\mathrm{ABX}+\mathrm{WM}$ & $\mathrm{ABX}+\mathrm{NUM}$ & UNDXBXover+WM & UNDXBXover+NUM \\
\hline Mean & 0.5353 & 0.1029 & 0.4533 & 0.0799 \\
\hline Best & 1.0000 & 1.0000 & 1.0000 & 1.0000 \\
\hline Std Dev & 0.4078 & 0.3027 & 0.4314 & 0.2737 \\
\hline
\end{tabular}

Table VII. Comparison between different operations for $f_{7}$ with different initial ranges of variables. All results are averaged ones over 50 runs. 
$f_{16}\left(\times 10^{-2}\right)$, number of iteration: 500

Initial range: $-2400 \leq x_{i} \leq 1200$

\begin{tabular}{|c|c|c|c|c|}
\hline & $\mathrm{ABX}+\mathrm{WM}$ & $\mathrm{ABX}+\mathrm{NUM}$ & UNDXBXover+WM & UNDXBXover+NUM \\
\hline Mean & 0.0837 & 4.7569 & 1.7523 & 5.9533 \\
\hline Best & 0.0013 & 0.0996 & 0.0029 & 0.0043 \\
\hline Std Dev & 0.2108 & 9.1365 & 6.9979 & 11.762 \\
\hline \multicolumn{5}{|c|}{ Initial range: $-6000 \leq x_{i} \leq 3000$} \\
\hline & $\mathrm{ABX}+\mathrm{WM}$ & $\mathrm{ABX}+\mathrm{NUM}$ & UNDXBXover+WM & UNDXBXover+NUM \\
\hline Mean & 0.0935 & 0.2158 & 1.1821 & 4.5950 \\
\hline Best & 0.0174 & 0.0048 & 0.0011 & 0.0146 \\
\hline Std Dev & 0.0871 & 0.2408 & 5.7730 & 10.320 \\
\hline \multicolumn{5}{|c|}{ Initial range: $-12000 \leq x_{i} \leq 6000$} \\
\hline & $\mathrm{ABX}+\mathrm{WM}$ & $\mathrm{ABX}+\mathrm{NUM}$ & UNDXBXover+WM & UNDXBXover+NUM \\
\hline Mean & 0.2869 & 0.7036 & 1.4933 & 7.5643 \\
\hline Best & 0.0142 & 0.0351 & 0.0072 & 0.1285 \\
\hline Std Dev & 0.4371 & 0.5949 & 6.5196 & 11.531 \\
\hline \multicolumn{5}{|c|}{ Initial range: $-24000 \leq x_{i} \leq 12000$} \\
\hline & $\mathrm{ABX}+\mathrm{WM}$ & $\mathrm{ABX}+\mathrm{NUM}$ & UNDXBXover+WM & UNDXBXover+NUM \\
\hline Mean & 1.3310 & 3.9503 & 3.2419 & 2.4231 \\
\hline Best & 0.0775 & 0.1872 & 0.0329 & 1.0387 \\
\hline Std Dev & 1.3098 & 5.0784 & 8.9199 & 30.433 \\
\hline
\end{tabular}

Table VIII. Comparison between different operations for $f_{16}$ with different initial ranges of variables. All results are averaged ones over 50 runs. 


\begin{tabular}{|c|c|c|c|c|c|c|c|}
\hline Unit & $P_{L, \min }(\mathrm{MW})$ & $P_{L, \max }(\mathrm{MW})$ & $a$ & $b$ & c & $e$ & $f$ \\
\hline 1 & 36 & 114 & 0.00690 & 6.73 & 94.705 & 100 & 100 \\
\hline 2 & 36 & 114 & 0.00690 & 6.73 & 94.705 & 100 & 100 \\
\hline 3 & 60 & 120 & 0.02028 & 7.07 & 309.54 & 100 & 100 \\
\hline 4 & 80 & 190 & 0.00942 & 8.18 & 369.03 & 150 & 150 \\
\hline 5 & 47 & 97 & 0.01142 & 5.35 & 148.89 & 120 & 120 \\
\hline 6 & 68 & 140 & 0.01142 & 8.05 & 222.33 & 100 & 100 \\
\hline 7 & 110 & 300 & 0.00357 & 8.03 & 287.71 & 200 & 200 \\
\hline 8 & 135 & 300 & 0.00492 & 6.99 & 391.98 & 200 & 200 \\
\hline 9 & 135 & 300 & 0.00573 & 6.60 & 455.76 & 200 & 200 \\
\hline 10 & 130 & 300 & 0.00605 & 12.9 & 722.82 & 200 & 200 \\
\hline 11 & 94 & 375 & 0.00515 & 12.9 & 635.20 & 200 & 200 \\
\hline 12 & 94 & 375 & 0.00569 & 12.8 & 654.69 & 200 & 200 \\
\hline 13 & 125 & 500 & 0.00421 & 12.5 & 913.40 & 300 & 300 \\
\hline 14 & 125 & 500 & 0.00752 & 8.84 & 1760.4 & 300 & 300 \\
\hline 15 & 125 & 500 & 0.00708 & 9.15 & 1728.3 & 300 & 300 \\
\hline 16 & 125 & 500 & 0.00708 & 9.15 & 1728.3 & 300 & 300 \\
\hline 17 & 220 & 500 & 0.00313 & 7.97 & 647.85 & 300 & 300 \\
\hline 18 & 220 & 500 & 0.00313 & 7.95 & 649.69 & 300 & 300 \\
\hline 19 & 242 & 550 & 0.00313 & 7.97 & 647.83 & 300 & 300 \\
\hline 20 & 242 & 550 & 0.00313 & 7.97 & 647.81 & 300 & 300 \\
\hline 21 & 254 & 550 & 0.00298 & 6.63 & 785.96 & 300 & 300 \\
\hline 22 & 254 & 550 & 0.00298 & 6.63 & 785.96 & 300 & 300 \\
\hline 23 & 254 & 550 & 0.00284 & 6.66 & 794.53 & 300 & 300 \\
\hline 24 & 254 & 550 & 0.00284 & 6.66 & 794.53 & 300 & 300 \\
\hline 25 & 254 & 550 & 0.00277 & 7.10 & 801.32 & 300 & 300 \\
\hline 26 & 254 & 550 & 0.00277 & 7.10 & 801.32 & 300 & 300 \\
\hline 27 & 10 & 150 & 0.52124 & 3.33 & 1055.1 & 120 & 120 \\
\hline 28 & 10 & 150 & 0.52124 & 3.33 & 1055.1 & 120 & 120 \\
\hline 29 & 10 & 150 & 0.52124 & 3.33 & 1055.1 & 120 & 120 \\
\hline 30 & 47 & 97 & 0.01140 & 5.35 & 148.89 & 120 & 120 \\
\hline 31 & 60 & 190 & 0.00160 & 6.43 & 222.92 & 150 & 150 \\
\hline 32 & 60 & 190 & 0.00160 & 6.43 & 222.92 & 150 & 150 \\
\hline 33 & 60 & 190 & 0.00160 & 6.43 & 222.92 & 150 & 150 \\
\hline 34 & 90 & 200 & 0.00010 & 8.95 & 107.87 & 200 & 200 \\
\hline 35 & 90 & 200 & 0.00010 & 8.62 & 116.58 & 200 & 200 \\
\hline 36 & 90 & 200 & 0.00010 & 8.62 & 116.58 & 200 & 200 \\
\hline 37 & 25 & 110 & 0.01610 & 5.88 & 307.45 & 80 & 80 \\
\hline 38 & 25 & 110 & 0.01610 & 5.88 & 307.45 & 80 & 80 \\
\hline 39 & 25 & 110 & 0.01610 & 5.88 & 307.45 & 80 & 80 \\
\hline 40 & 242 & 550 & 0.00313 & 7.97 & 647.83 & 300 & 300 \\
\hline
\end{tabular}

Table IX. Units Data (40 systems with valve-point loadings): $a\left(\$ / \mathrm{MW}^{2} \mathrm{~h}\right), b(\$ / \mathrm{MWh}), c(\$ / \mathrm{h}), e(\$ / \mathrm{h})$, and $f(\mathrm{rad} / \mathrm{MW})$ are cost coefficients.

\begin{tabular}{ccccc}
\hline & ABX+WM & ABX+NUM & UNDXBXover+WM & UNDXBXover+NUM \\
\hline Ave. Cost & $\mathbf{1 2 2 8 1 1 . 4 1}$ & 122840.26 & 124130.58 & 124223.25 \\
\hline Best Cost & $\mathbf{1 2 1 9 1 5 . 9 3}$ & 122232.21 & 122763.44 & 123642.92 \\
\hline Worst Cost & $\mathbf{1 2 3 3 3 4 . 0 0}$ & 123532.57 & 125092.30 & 124636.30 \\
\hline Std. Dev. & $\mathbf{3 1 3 . 7 9}$ & 333.36 & 818.10 & 805.12 \\
\hline$t$-test $([\mathrm{ABX}+\mathrm{WM}]-[$ UNDXBXover+NUM]) $=-11.55$ & & \\
\hline
\end{tabular}

Table X. Statistical results for ELD with a load demand of 10500MW. 


\begin{tabular}{|c|c|c|c|c|}
\hline$P_{L_{i}}(\mathrm{MW}), i=$ & $\mathrm{ABX}+\mathrm{WM}$ & $\mathrm{ABX}+\mathrm{NUM}$ & UNDXBXover+WM & UNDXBXover+NUM \\
\hline 1 & 110.97 & 81.82 & 110.95 & 83.56 \\
\hline 2 & 110.88 & 112.69 & 111.20 & 110.84 \\
\hline 3 & 98.17 & 98.03 & 99.25 & 97.44 \\
\hline 4 & 178.85 & 179.84 & 179.75 & 129.88 \\
\hline 5 & 87.78 & 87.92 & 90.01 & 87.80 \\
\hline 6 & 140.00 & 105.49 & 139.96 & 105.44 \\
\hline 7 & 260.37 & 259.57 & 265.71 & 259.67 \\
\hline 8 & 286.83 & 285.45 & 286.60 & 285.00 \\
\hline 9 & 285.14 & 284.23 & 284.64 & 211.63 \\
\hline 10 & 204.86 & 203.59 & 204.82 & 258.57 \\
\hline 11 & 165.98 & 168.81 & 168.81 & 168.68 \\
\hline 12 & 167.75 & 94.00 & 243.62 & 243.57 \\
\hline 13 & 214.31 & 304.53 & 304.56 & 394.27 \\
\hline 14 & 305.65 & 394.11 & 304.54 & 304.47 \\
\hline 15 & 393.66 & 394.43 & 394.28 & 304.52 \\
\hline 16 & 394.60 & 394.53 & 394.28 & 484.02 \\
\hline 17 & 489.22 & 489.47 & 400.03 & 399.61 \\
\hline 18 & 489.25 & 489.25 & 399.70 & 489.27 \\
\hline 19 & 511.23 & 511.18 & 511.33 & 511.27 \\
\hline 20 & 510.69 & 511.26 & 511.58 & 511.28 \\
\hline 21 & 524.74 & 523.39 & 523.55 & 523.33 \\
\hline 22 & 525.52 & 523.43 & 526.32 & 523.28 \\
\hline 23 & 522.98 & 524.18 & 523.52 & 523.39 \\
\hline 24 & 523.22 & 524.24 & 530.03 & 523.41 \\
\hline 25 & 523.26 & 523.96 & 523.28 & 523.48 \\
\hline 26 & 523.32 & 523.33 & 523.39 & 523.30 \\
\hline 27 & 10.00 & 10.00 & 10.92 & 10.38 \\
\hline 28 & 10.00 & 10.00 & 10.29 & 10.49 \\
\hline 29 & 10.00 & 10.00 & 11.14 & 10.24 \\
\hline 30 & 88.86 & 89.50 & 94.38 & 89.33 \\
\hline 31 & 162.30 & 160.10 & 170.87 & 160.34 \\
\hline 32 & 177.94 & 159.96 & 161.74 & 159.78 \\
\hline 33 & 160.18 & 163.09 & 182.87 & 165.00 \\
\hline 34 & 166.54 & 165.05 & 172.89 & 164.80 \\
\hline 35 & 164.80 & 169.30 & 177.58 & 169.58 \\
\hline 36 & 170.68 & 170.48 & 165.67 & 183.22 \\
\hline 37 & 108.17 & 89.16 & 89.78 & 90.24 \\
\hline 38 & 100.68 & 108.73 & 93.91 & 108.69 \\
\hline 39 & 109.34 & 90.19 & 90.76 & 85.46 \\
\hline 40 & 511.28 & 511.51 & 511.29 & 511.27 \\
\hline Total Power & 10500 & 10500 & 10500 & 10500 \\
\hline Total Cost (\$h) & 121915.93 & 122232.21 & 122763.44 & 123642.92 \\
\hline
\end{tabular}

Table XI. The optimal dispatch solution for different approaches.

\begin{tabular}{ccccc}
\hline \multicolumn{4}{c}{ MSE $\left(\times 10^{-4}\right)$, number of iteration: 2000} \\
\hline ABX+WM & ABX+NUM & UNDXBXover+WM & UNDXBXover+NUM \\
\hline Mean & $\mathbf{3 . 3 9 3 9}$ & 4.7965 & 7.4178 & 9.5312 \\
Best & $\mathbf{2 . 5 1 5 4}$ & 2.8983 & 4.1872 & 5.8292 \\
Std Dev & $\mathbf{0 . 4 7 2 8}$ & 0.9566 & 2.1383 & 1.6943 \\
$t$-test $([\mathrm{ABX}+\mathrm{WM}]-[$ UNDXBXover+NUM]) $=-24.67$ & & \\
\hline
\end{tabular}

Table XII. Statistical results for the example of associative memory 


\section{A. Benchmark test function}

The 18 benchmark test functions for testing the RCGA performance are listed below. In these functions, $\mathbf{x}=\left[\begin{array}{llll}x_{1} & x_{2} & \cdots & x_{n}\end{array}\right]$.

\section{Unimodal Functions:}

\section{Sphere Model}

$$
f_{1}(\mathbf{x})=\sum_{i=1}^{30} x_{i}^{2},-50 \leq x_{i} \leq 150, \min \left(f_{1}\right)=f_{1}(\mathbf{0})=0
$$

\section{Generalized Rosenbrock’s Function}

$$
f_{2}(\mathbf{x})=\sum_{i=1}^{29}\left[100\left(x_{i+1}-x_{i}^{2}\right)^{2}+\left(x_{i}-1\right)^{2}\right],-2.048 \leq x_{i} \leq 2.048, \min \left(f_{2}\right)=f_{2}(\mathbf{1})=0
$$

\section{Step Function}

$$
f_{3}(\mathbf{x})=\sum_{i=1}^{30}\left(\left[x_{i}+0.5\right\rfloor\right)^{2},-5 \leq x_{i} \leq 10, \min \left(f_{3}\right)=f_{3}(\mathbf{0})=0
$$

\section{Quartic Function (with noise)}

$$
f_{4}(\mathbf{x})=\sum_{i=1}^{30} i x_{i}^{4}+\operatorname{random}[0, \quad 1),-1.28 \leq x_{i} \leq 2.56, \min \left(f_{4}\right)=f_{4}(\mathbf{0})=0
$$

where random $[0,1)$ generates uniformly a floating-point number between 0 and 1.

\section{Schwefel's Problem 2.21}

$$
f_{5}(\mathbf{x})=\max _{i}\left\{\left|x_{i}\right|, 1 \leq i \leq 30\right\},-150 \leq x_{i} \leq 50, \min \left(f_{5}\right)=f_{5}(\mathbf{0})=0
$$

\section{Schwefel's Problem 2.22}

$$
f_{6}(\mathbf{x})=\sum_{i=1}^{30}\left|x_{i}\right|+\prod_{i=1}^{30}\left|x_{i}\right|,-5 \leq x_{i} \leq 15, \min \left(f_{6}\right)=f_{6}(\mathbf{0})=0
$$


Multimodal Functions with Only a Few Local Minima:

\section{Eason's Function}

$f_{7}(\mathbf{x})=-\cos \left(x_{1}\right) \cdot \cos \left(x_{2}\right) \cdot \exp \left(-\left(\left(x_{1}-\pi\right)^{2}+\left(x_{2}-\pi\right)^{2}\right)\right),-300 \leq x_{1}, x_{2} \leq 300$,

$\min \left(f_{7}\right)=f_{7}([\pi, \pi])=-1$,

8. Shekel's Foxholes Function

$f_{8}(\mathbf{x})=\left[\frac{1}{500}+\sum_{j=1}^{25} \frac{1}{j+\sum_{i=1}^{2}\left(x_{i}-a_{i j}\right)^{6}}\right]^{-1},-65.536 \leq x_{i} \leq 65.536, \min \left(f_{8}\right)=f_{8}([-32,-32]) \approx 1$,

where

$a_{i j}=\left(\begin{array}{cccccccccc}-32 & -16 & 0 & 16 & 32 & -32 & \cdots & 0 & 16 & 32 \\ -32 & -32 & -32 & -32 & -32 & -16 & \cdots & 32 & 32 & 32\end{array}\right)$

9. Kowalik's Function

$f_{9}(\mathbf{x})=\sum_{i=1}^{9}\left[a_{i}-\frac{x_{1}\left(b_{i}^{2}+b_{i} x_{2}\right)}{b_{i}^{2}+b_{i} x_{3}+x_{4}}\right]^{2},-5 \leq x_{i} \leq 5$,

$\min \left(f_{9}\right)=f_{9}\left(\left[\begin{array}{lll}0.1928, & 0.1908, \quad 0.1231, & 0.1358]\end{array}\right) \approx 0.0003075\right.$

where

\begin{tabular}{|c|c|c|}
\hline$i$ & $a_{i}$ & $b_{i}$ \\
\hline 1 & 0.1957 & 4 \\
\hline 2 & 0.1947 & 2 \\
\hline 3 & 0.1735 & 1 \\
\hline 4 & 0.1600 & $1 / 2$ \\
\hline 5 & 0.0844 & $1 / 4$ \\
\hline 6 & 0.0627 & $1 / 6$ \\
\hline 7 & 0.0456 & $1 / 8$ \\
\hline 8 & 0.0342 & $1 / 10$ \\
\hline 9 & 0.0323 & $1 / 12$ \\
\hline 10 & 0.0235 & $1 / 14$ \\
\hline 11 & 0.0246 & $1 / 16$ \\
\hline
\end{tabular}

10. Maxican hat Function

$$
f_{10}(\mathbf{x})=-\frac{\sin \left(x_{1}\right) \sin \left(x_{2}\right)}{x_{1} x_{2}},-5 \leq x_{1}, x_{2} \leq 15, \min \left(f_{10}\right)=\lim _{x \rightarrow(0,0)} f_{10}(\mathbf{x})=0
$$

\section{Six-Hump Camel Back Function}


$f_{11}(\mathbf{x})=4 x_{1}^{2}-2.1 x_{1}^{4}+\frac{1}{3} x_{1}^{6}+x_{1} x_{2}-4 x_{2}^{2}+4 x_{2}^{4},-5 \leq x_{1}, x_{2} \leq 5 ，$

$\min \left(f_{11}\right)=f_{11}([0.08983, \quad-0.7126])=f_{11}\left(\left[\begin{array}{lll}-0.08983, & 0.7126\end{array}\right] \approx-1.0316\right.$

\section{Hartman's Family I}

$f_{12}(\mathbf{x})=-\sum_{i=1}^{4} c_{i} \exp \left[-\sum_{j=1}^{3} a_{i j}\left(x_{j}-p_{i j}\right)^{2}\right], 0 \leq x_{i} \leq 1$,

$\min \left(f_{12}\right)=f_{12}([0.114, \quad 0.556, \quad 0.852]) \approx-3.8628$,

where

\begin{tabular}{|c|c|c|c|c|c|c|}
\hline & \multicolumn{3}{|c|}{$a_{i j}$} & \multicolumn{3}{c|}{$p_{i j}$} \\
\hline$\searrow^{j}$ & 1 & 2 & 3 & 1 & 2 & 3 \\
\hline 1 & 3 & 10 & 30 & 0.3689 & 0.1170 & 0.2673 \\
\hline 2 & 0.1 & 10 & 35 & 0.4699 & 0.4387 & 0.7470 \\
\hline 3 & 3 & 10 & 30 & 0.1091 & 0.8732 & 0.5547 \\
\hline 4 & 0.1 & 10 & 35 & 003815 & 0.5743 & 0.8828 \\
\hline
\end{tabular}

\begin{tabular}{|c|c|}
\hline$i$ & $c_{i}$ \\
\hline & \\
\hline 1 & 1 \\
\hline 2 & 1.2 \\
\hline 3 & 3 \\
\hline 4 & 3.2 \\
\hline
\end{tabular}

\section{Hartman's Family II}

$$
f_{13}(\mathbf{x})=-\sum_{i=1}^{4} c_{i} \exp \left[-\sum_{j=1}^{6} a_{i j}\left(x_{j}-p_{i j}\right)^{2}\right], 0 \leq x_{i} \leq 1,
$$

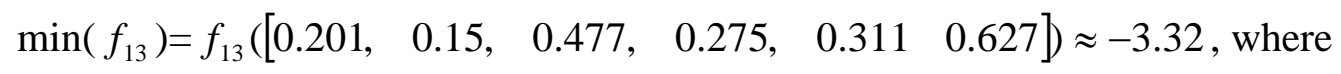

\begin{tabular}{|c|c|c|c|c|c|c|c|c|c|c|c|c|}
\hline & \multicolumn{9}{|c|}{$a_{i j}$} & \multicolumn{7}{c|}{$p_{i j}$} \\
\hline$j$ & 1 & 2 & 3 & 4 & 5 & 6 & 1 & 2 & 3 & 4 & 5 & 6 \\
\hline 1 & 10 & 3 & 17 & 3.5 & 1.7 & 8 & 0.1312 & 0.1696 & 0.5569 & 0.0124 & 0.8283 & 0.5886 \\
\hline 2 & 0.05 & 10 & 17 & 0.1 & 8 & 14 & 0.2329 & 0.4135 & 0.8307 & 0.3736 & 0.1004 & 0.9991 \\
\hline 3 & 3 & 3.5 & 1.7 & 10 & 17 & 8 & 0.2348 & 0.1415 & 0.3522 & 0.2883 & 0.3047 & 0.6650 \\
\hline 4 & 17 & 8 & 0.05 & 10 & 0.1 & 14 & 0.4047 & 0.8828 & 0.8732 & 0.5743 & 0.1091 & 0.0381 \\
\hline
\end{tabular}

\begin{tabular}{|c|c|}
\hline$i$ & $c_{i}$ \\
\hline & \\
\hline 1 & 1 \\
\hline 2 & 1.2 \\
\hline 3 & 3 \\
\hline 4 & 3.2 \\
\hline
\end{tabular}


Multimodal Functions with Many Local Minima:

\section{Generalized Penalized Functions}

$$
\begin{aligned}
& f_{14}(\mathbf{x})=0.1\left\{\sin ^{2}\left(\pi 3 x_{1}\right)+\sum_{i=1}^{29}\left(x_{i}-1\right)^{2} \cdot\left[1+\sin ^{2}\left(3 \pi x_{i+1}\right)\right]+\left(x_{30}-1\right)^{2}\left[1+\sin ^{2}\left(2 \pi x_{30}\right)\right]\right\} \\
& +\sum_{i=1}^{30} u\left(x_{i}, 5,100,4\right), \\
& -50 \leq x_{i} \leq 50, \min \left(f_{14}\right)=f_{14}(\mathbf{1})=0
\end{aligned}
$$

where

$$
u\left(x_{i}, a, k, m\right)=\left\{\begin{array}{lc}
k\left(x_{i}-a\right)^{m}, & x_{i}>a, \\
0, & -a \leq x_{1} \leq a \\
k\left(-x_{i}-a\right)^{m}, & x_{i}<a
\end{array}\right.
$$

\section{Generalized Rastrigin’s Function}

$$
f_{15}(\mathbf{x})=\sum_{i=1}^{30}\left[x_{i}^{2}-10 \cos \left(2 \pi x_{i}\right)+10\right],-5.12 \leq x_{i} \leq 10.24, \min \left(f_{15}\right)=f_{15}(\mathbf{0})=0
$$

\section{Generalized Griewank Function}

$$
f_{16}(\mathbf{x})=\frac{1}{4000} \sum_{i=1}^{30} x_{i}^{2}-\prod_{i=1}^{30} \cos \left(\frac{x_{i}}{\sqrt{i}}\right)+1, \quad-1200 \leq x_{i} \leq 600, \min \left(f_{16}\right)=f_{16}(\mathbf{0})=0
$$

\section{Ackley’s Function}

$$
f_{17}(\mathbf{x})=-20 \exp \left(-0.2 \sqrt{\frac{1}{30} \sum_{i=1}^{30} x_{i}^{2}}\right)-\exp \left(\frac{1}{30} \sum_{i=1}^{30} \cos 2 \pi x_{i}\right)+20+e,-64 \leq x_{i} \leq 32,
$$

$\min \left(f_{17}\right)=f_{17}(\mathbf{0})=0$

\section{Schwefel's Function}

$$
\begin{aligned}
& f_{18}(\mathbf{x})=-\sum_{i=1}^{30}\left(x_{i} \sin \left(\sqrt{\left|x_{i}\right|}\right)\right),-500 \leq x_{i} \leq 500, \\
& \min \left(f_{18}\right)=f_{18}([420.9687, \quad \cdots \quad 420.9687])=-30 \times 418.9829=-12569.5
\end{aligned}
$$




\section{B. Unimodal normal distribution crossover (UNDX)}

Unimodal normal distribution crossover is defined as a mixture of three selected parents $\mathbf{p}_{1}$, $\mathbf{p}_{2}$, and $\mathbf{p}_{3}$. The resulting offspring $\mathbf{o}_{\mathbf{s}_{c}}$ is defined as,

$$
\begin{aligned}
& \mathbf{o}_{\mathbf{s}_{c}^{1}}=\left[\begin{array}{llll}
o_{s_{1}^{1}} & o_{s_{2}^{1}} & \cdots & o_{s_{n o_{-} \text {vars }}^{1}}
\end{array}\right]=\mathbf{m}+z_{1} e_{1}+\sum_{i=2}^{n o-\text { vars }} \mathrm{z}_{\mathrm{i}} e_{i}, \\
& \mathbf{o}_{\mathbf{s}_{c}^{2}}=\left[\begin{array}{llll}
o_{s_{1}^{1}} & o_{s_{2}^{1}} & \cdots & o_{s_{n o}^{1} \text { vars }}
\end{array}\right]=\mathbf{m}-z_{1} e_{1}-\sum_{i=2}^{n o-\text { vars }} \mathrm{z}_{\mathrm{i}} e_{i},
\end{aligned}
$$

where

$$
\mathbf{m}=\frac{\left(\mathbf{p}_{1}+\mathbf{p}_{2}\right)}{2}
$$

$z_{1}=N\left(0, \sigma_{1}^{2}\right), \quad z_{i}=N\left(0, \sigma_{2}^{2}\right)$,

$$
\sigma_{1}=\beta d_{1}, \quad \sigma_{2}=\frac{\mu d_{2}}{\sqrt{\text { no_vars }}}
$$

$$
e_{1}=\frac{\left(\mathbf{p}_{2}-\mathbf{p}_{1}\right)}{\left|\mathbf{p}_{2}-\mathbf{p}_{1}\right|},
$$

$e_{m} \perp e_{n}(m \neq n), \quad m, n=1, \ldots$, no_vars,

where $N(\cdot)$ is a normal distributed random number, $d_{1}$ is the distance between the parents $\mathbf{p}_{1}$ and $\mathbf{p}_{2}, d_{2}$ is the distance of $\mathbf{p}_{3}$ from the line connecting $\mathbf{p}_{1}$ and $\mathbf{p}_{2}, \beta$ and $\mu$ are constant.

\section{Blend crossover $(B L X-\alpha)$}

Blend crossover is defined as a combination of two selected parents $\mathbf{p}_{1}$ and $\mathbf{p}_{2}$. The resulting offspring $\mathbf{o}_{\mathrm{s}_{c}}=\left[\begin{array}{llll}O_{s_{1}}, & o_{s_{2}}, \cdots, o_{s_{n o_{-} \text {var }}}\end{array}\right]$ is chosen randomly from the interval $\left[X_{i}^{1}, X_{i}^{2}\right]$ following the uniform distribution, where

$$
\begin{aligned}
& X_{i}^{1}=\min \left(p_{1_{i}}, p_{2_{i}}\right)-\alpha d_{i}, \\
& X_{i}^{2}=\max \left(p_{1_{i}}, p_{2_{i}}\right)+\alpha d_{i},
\end{aligned}
$$

where 
$d_{i}=\left|p_{1_{i}}-p_{2_{i}}\right|, p_{1_{i}}$ and $p_{2_{i}}$ are the $i$-th elements of $\mathbf{p}_{1}$ and $\mathbf{p}_{2}$ respectively, and $\alpha$ is a positive constant.

\section{Non-uniform mutation (NUM)}

Non-uniform mutation is an operation with a fine-tuning capability. Its action depends on the generation number of the population. The operation takes place as follows. If $\mathbf{o}_{\mathrm{s}}=\left[\begin{array}{llll}O_{s_{1}}, & O_{s_{2}}, \ldots, & O_{s_{n o \text { var }}}\end{array}\right]$ is a chromosome and the element $o_{s_{k}}$ is randomly selected for mutation (the value of $o_{s_{k}}$ is inside [ $\operatorname{para}_{\text {min }}^{k}, \operatorname{para}_{\max }^{k}$ ]), the resulting chromosome is then given by $\hat{\mathbf{o}}_{\mathbf{s}}=\left[o_{s_{1}}, \ldots, \hat{o}_{s_{k}}, \ldots, o_{s_{n o-} \text { vars }}\right], k \in 1,2, \ldots$ no_vars, and

$\hat{o}_{s_{k}}=\left\{\begin{array}{l}o_{s_{k}}+\Delta\left(\tau, \text { para }_{\max }^{k}-o_{s_{k}}\right) \text { if } r_{d}=0 \\ o_{s_{k}}-\Delta\left(\tau, o_{s_{k}}-\text { para }_{\min }^{k}\right) \text { if } r_{d}=1\end{array}\right.$,

where $r_{d}$ is a random number equal to 0 or 1 only. The function $\Delta(\tau, y)$ returns a value in the range $[0, y]$ such that $\Delta(\tau, y)$ approaches 0 as $\tau$ increases. It is defined as follows,

$\Delta(\tau, y)=y\left(1-r^{\left(1-\frac{\tau}{T}\right)^{b}}\right)$

where $r$ is a random number in [0,1], $\tau$ is the present generation number of the population, $T$ is the maximum generation number of the population, and $b$ is a system parameter that determines the degree of non-uniformity. 